\title{
The Rise of Manganese-Catalyzed Reduction Reactions
}

\author{
Peter Schlichter ${ }^{\mathrm{a}, \mathrm{b}}$ (1) \\ Christophe Werlé*a,c (iD \\ a Max Planck Institute for Chemical Energy Conversion, \\ Stiftstr. 34-36, 45470 Mülheim an der Ruhr, Germany \\ christophe.werle@cec.mpg.de \\ ${ }^{b}$ Institut für Technische und Makromolekulare Chemie \\ (ITMC), RWTH Aachen University, Worringer Weg 2, \\ 52074 Aachen, Germany \\ ' Ruhr University Bochum, Universitätsstr. 150, 44801 \\ Bochum, Germany
}

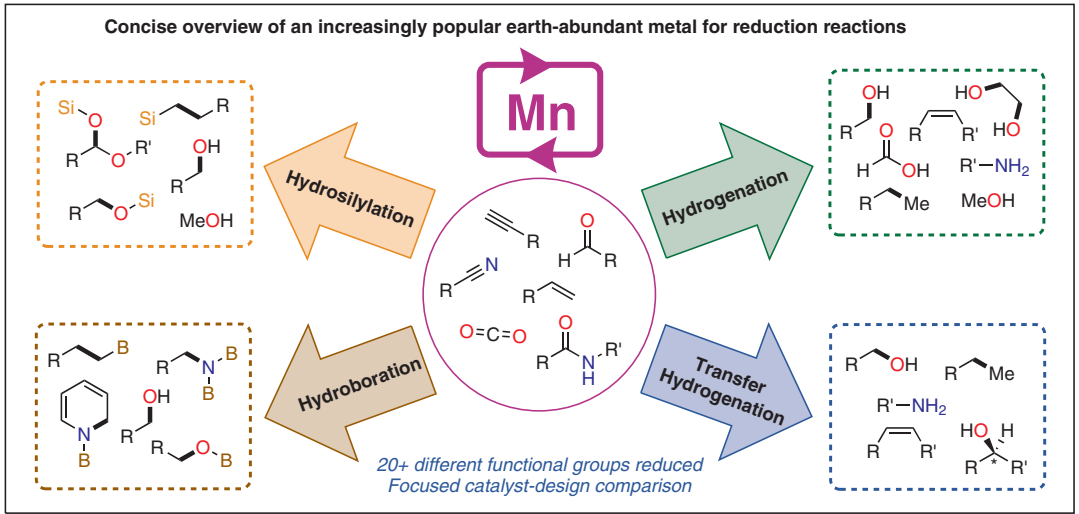

Received: 17.08.2021

Accepted after revision: 09.09.2021

Published online: 29.09 .2021

DOI: 10.1055/a-1657-2634; Art ID: ss-2021-r0495-r

License terms: (C) (P)

(c) 2022. The Author(s). This is an open access article published by Thieme under the terms of the Creative Commons Attribution License, permitting unrestricted use, distribution and reproduction, so long as the original work is properly cited.

(https://creativecommons.org/licenses/by/4.0/)

Abstract Recent developments in manganese-catalyzed reducing transformations-hydrosilylation, hydroboration, hydrogenation, and transfer hydrogenation-are reviewed herein. Over the past half a decade (i.e., 2016 to the present), more than 115 research publications have been reported in these fields. Novel organometallic compounds and new reduction transformations have been discovered and further developed. Significant challenges that had historically acted as barriers for the use of manganese catalysts in reduction reactions are slowly being broken down. This review will hopefully assist in developing this research area, by presenting a clear and concise overview of the catalyst structures and substrate transformations published so far.

1 Introduction

Hydrosilylation

Hydroboration

Hydrogenation

Transfer Hydrogenation

Conclusion and Perspective

Key words manganese, reduction, homogeneous catalysis, hydrogenation, hydrosilylation, hydroboration, transfer hydrogenation

\section{Introduction}

Manganese is the 12th most abundant element in the earth's crust ${ }^{1}$ and is currently (2020) produced on an 18.5 million metric ton scale per year. ${ }^{2}$ Manganese has many applications, the most prominent being in the steel- and ironmaking industries. ${ }^{3}$ A unique property is that it can be found in a large range of oxidation states $(-3$ to +7$)$, allow- ing it to play essential roles in assisting chemical synthesis. Manganese is found in many enzymes vital to sustaining life on earth; most notable is its role in the core of oxygenevolving complexes, which assist in splitting water to produce oxygen in plants. ${ }^{4}$ In the lab, manganese-catalyzed oxidation reactions, ${ }^{5}$ radical cyclization reactions, ${ }^{6}$ and $\mathrm{C}-\mathrm{H}$ activation reactions, ${ }^{7}$ to name a few, demonstrate the chemical potential of this group 7 transition metal. With a growing interest in creating more sustainable chemistry in the future, both catalysis and manganese have been placed under the limelight. Recently, manganese's role in homogenous catalysis has been increasingly discussed in reviews ${ }^{8}$ as well as book chapters. ${ }^{9}$

The reduction of organic molecules is an important chemical tool in synthesizing novel high-value chemicals as well as bulk precursor molecules. The latter, in particular, has seen increasing attention due to the potential of green hydrogen to recycle carbon dioxide in the building of a methanol-based economy. ${ }^{10}$ There are many known methods to add hydrogen across unsaturated $\pi$-bonds. Herein, we will focus exclusively on the homogeneous manganese catalysts able to perform four important reduction reactions: hydrosilylation, hydroboration, hydrogenation, and transfer hydrogenation.

Hydrosilylation and hydroboration reactions make use of silanes or boranes, which themselves are weak hydride sources. In the presence of a catalyst, the activation of these readily available precursors affords the silylated or boronated species under mild reaction conditions. In the case of $\mathrm{C}-\mathrm{C}$ $\pi$-bond reduction, these functionalized products are highly useful precursors for cross-coupling reactions, predominantly Suzuki ${ }^{11}$ and Hiyama cross-couplings. When used to reduce a polar $C-X \pi$-bond ( $X=$ nitrogen, oxygen), the reduced functionalized products can be readily hydrolyzed to 
produce the unfunctionalized reduced organic compound. Hydrogenation uses hydrogen gas as a reductant. With complete atom economy (in principle), hydrogenation is the most efficient reduction method. Transfer hydrogenation adds two hydrogen atoms across an unsaturated bond, given by a sacrificial organic source (commonly ${ }^{i} \mathrm{PrOH}$ ). The major advantages of this reduction method are the availability of the hydrogen source, which often also serves as the solvent, and the mild reaction conditions, which are often low temperature and do not require specific pressuresafe equipment; this is particularly advantageous for small scale, laboratory systems.

Several significant breakthroughs have occurred in recent times, which have unleashed manganese's potential in reducing organic substrates. Particularly, the synthesis of low-valent $\mathrm{Mn}(\mathrm{I})$ and $\mathrm{Mn}(\mathrm{II})$ pincer complexes and the utilization of metal-ligand cooperation (MLC) ${ }^{12}$ in manganese complexes have allowed the activation of reductants and substrates previously not possible. From a few initial examples, half a decade ago, the list of reduction transformations is now significant (vide infra). ${ }^{13}$

The growth of manganese pincer complexes as a complete topic was first reviewed by Beller in $2017^{14}$ and then by Milstein in $2018 .{ }^{15}$ Since then, several reviews have included hydrogenation of manganese complexes in comparison to other base metals. ${ }^{16}$ Reviews that focus primarily on manganese include an early (2017) review on manganese (de)hydrogenation reactions, ${ }^{17}$ a review on hydrosilylation from Wang et al. in 2018, ${ }^{18}$ a book chapter on MLC in Mn(I) hydrogenation, ${ }^{12 \mathrm{~b}}$ and, more current, in-depth reviews on transfer hydrogenation from Bastin and Sortais ${ }^{19}$ and hydrogenation from Liu. ${ }^{20}$ So far, no concise overview of all the latest developments of manganese-catalyzed reduction reactions across different major reducing platforms exists.

This review has three main objectives: (a) to provide a concise overview of the literature in the four reduction methods mentioned above, (b) to show the potential of manganese as a catalyst for future reduction use, and (c) to offer insight into the current major catalytic design constraints and requirements for the development of novel catalytic systems and complexes. Each reduction method is broken down into three subsections: a short introduction of early examples, an overview of the known manganese catalysts able to perform the broad transformation, and a concise summary of the substrates that have been shown to be reduced using that method.

\section{Hydrosilylation}

Manganese-catalyzed hydrosilylation reactions are the oldest known reduction reactions covered in this review. Back in 1983, Faltynek et al. showed that a silylpentacarbonylmanganese(I) species could reduce terminal alkenes via thermal or photochemical activation to their corresponding alkylsiloxane with heptamethylcyclotetrasiloxane (HMCTS). ${ }^{21}$ While the photochemical reaction cleanly produced the desired product, the thermally activated system

\section{Biographical Sketches}

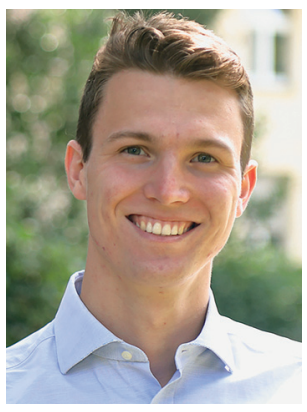

Peter Schlichter studied chemistry at the University of York, where he obtained his Master's degree, MChem, in 2019. During his Master's project working in the group of Prof. Dr. M. North in the field of

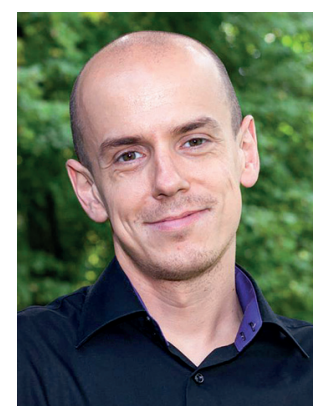

Christophe Werlé is a Max Planck Research Group Leader at the Max Planck Institute for Chemical Energy Conversion, working in collaboration with the Ruhr University Bochum. He leads the independent Max Planck research group Synergistic Organometallic Catalysis. In 2014, he obtained his doctoral green organic chemistry, he focused on using bio-based platform molecules for application in the synthesis of polymers. Afterwards, he joined the group of Prof. Dr. Walter Leitner at the Max Planck Institute for Chemi- cal Energy Conversion (MPI(EC), where he is currently doing Ph.D. studies with affiliation to RWTH Aachen. His research currently concentrates on the development of manganesecatalyzed transformations. degree from the University of Strasbourg (2011-2014). He then served as a postdoctoral researcher, first in the group of Prof. Dr. Alois Fürstner (20142016) and then in the group of Prof. Dr. Karsten Meyer (20162017). In September 2017, he joined the department of Molecular Catalysis of Prof. Dr. Wal- ter Leitner as group leader of Organometallic Electrocatalysis (2017-2019) and began his independent career in September 2019. Research in the Werlé group focuses on developing a molecular-level control of bond activation processes and catalysis via transition metal-based systems. 
produced a mixture of products unselectively. Furthermore, it was shown that manganese itself was not the active catalytic component; instead, the Mn-Si bond was homolytically cleaved to afford the active silyl radical. The group of Hilal (1987) used decacarbonyldimanganese(0) in the presence of silanes to produce an active $\mathrm{Mn}(\mathrm{I})$ hydride, to reduce hexene under much milder conditions ( $40{ }^{\circ} \mathrm{C}$ vs. 180 $\left.{ }^{\circ} \mathrm{C}\right) .{ }^{22}$ Almost a decade later, Cutler used a $\mathrm{Mn}(\mathrm{I})$ acetyl complex to hydrosilylate esters to ethers via a deoxygenative reduction and, a year later, reduce ketones to secondary alcohols. ${ }^{23}$ Particularly these early examples from the group of Cutler showed the promise of low-valent manganese catalysts with loadings of $2.4 \mathrm{~mol} \%$ enabling the reduction of acetophenone in less than 4 minutes.

\subsection{Catalyst Overview}

A large spread of oxidation states has been used as precatalysts for manganese-catalyzed hydrosilylation reactions (notable examples summarized in Figure 1). As expected, many of these catalysts are active through a variety of different mechanisms and activation pathways. Both photochemical and thermal activation have been used depending on the catalyst, the silane, and the substrate. The divergent approaches to $\mathrm{Mn}(\mathrm{III})$ hydrosilylation are great examples of the many possible catalytic cycles. The $\mathrm{Mn}(\mathrm{V})$ pre-catalyst 6 reported by Du et al. is reduced to form a supposed Mn(III) active catalyst. ${ }^{24}$ In contrast, Lugan, Darcel, and Sortais suggested that their $\mathrm{Mn}(\mathrm{I})$ pre-catalyst 3 requires oxidative addition of the silane to give a $\mathrm{Mn}$ (III) intermediate before photochemical CO dissociation affords the active catalyst. ${ }^{25}$ Alternatively, Mn(III) pre-catalyst $\mathbf{5}$ was used as early as 2000 by Magnus and co-workers to reduce $\alpha, \beta$-unsaturated ketones. ${ }^{26} \mathrm{Mn}(0)$ pre-catalysts have also been used for a range of hydrosilylation reactions. Sortais and Darcel used UV light to activate $\mathbf{1}$ for the reduction of both esters and acids to their respective aldehydes. ${ }^{27}$ In both cases, no activity was observed with thermal activation (even at $100{ }^{\circ} \mathrm{C}$ ), in agreement with reports by Fuchikami for ester reduction. ${ }^{28}$ In contrast, it has been suggested in multiple early reports that the dimanganese carbonyl complex $\mathbf{1}$ can form the known $\mathrm{Mn}(\mathrm{I})$ reducing species $\mathrm{HMn}(\mathrm{CO})_{5}$ upon reaction with a tertiary silane at high temperature. ${ }^{29}$ The group of Fuchikami used $\mathrm{Mn}_{2}(\mathrm{CO})_{10}$ at $100{ }^{\circ} \mathrm{C}$ in the presence of diethylamine for amide reduction and, recently, the Mn(I) hydride was also proposed as the active species in the hydrosilylation of alkenes presented by Xie and co-workers. ${ }^{30}$ Whether the photochemical hydrosilylation using decacarbonyldimanganese $(0)$ also has the same activation to a $\mathrm{Mn}(\mathrm{I})$ hydride is, as yet, unknown. Contrary to examples presented so far, other catalysts do not exhibit oxidation or reduction of the metal center in the activation step or throughout the catalytic cycle. Mechanistic studies from the group of Trovitch show that their redox non-innocent $\mathrm{Mn}(\mathrm{II})$ complex 4 was able to insert into the $\mathrm{Si}-\mathrm{H} \sigma$-bond without a change in oxidation state. ${ }^{31}$ In addition, the group of Royo studied their $\mathrm{Mn}(\mathrm{I})$ hydrosilylation reaction mixture by ${ }^{55} \mathrm{Mn}$ NMR spectroscopy and identified three active manganese species with a suggested oxidation state of +1 (vide infra). ${ }^{32}$ Likewise, Werlé et al. suggested no change from the $\mathrm{Mn}(\mathrm{I})$ oxidation state and an $\eta^{2} \mathrm{Si}-\mathrm{H}$ manganese coordination as the most likely activation pathway of phenylsilane by $\operatorname{MnBr}(\mathrm{CO})_{5}$, instead of oxidative addition. ${ }^{33}$

\subsection{Development of Manganese-Catalyzed Hydro- silylation Reactions}

In 2000, Magnus continued the work of Hilal and Faltynek on the hydrosilylation of olefin bonds using manganese. ${ }^{26}$ By using $\mathrm{Mn}(\mathrm{dpm})_{3}$ (i.e., catalyst 5, dpm = dipivaloylmethanato, Figure 1) in an isopropanol solvent and with phenylsilane as reductant, $\alpha, \beta$-unsaturated ketones could be reduced to saturated unfunctionalized ketones. In 2016, Shenvi and co-workers clarified the reaction by showing that a highly active reducing agent, isopropoxy(phenyl)silane, was formed in situ. ${ }^{34}$ The group also

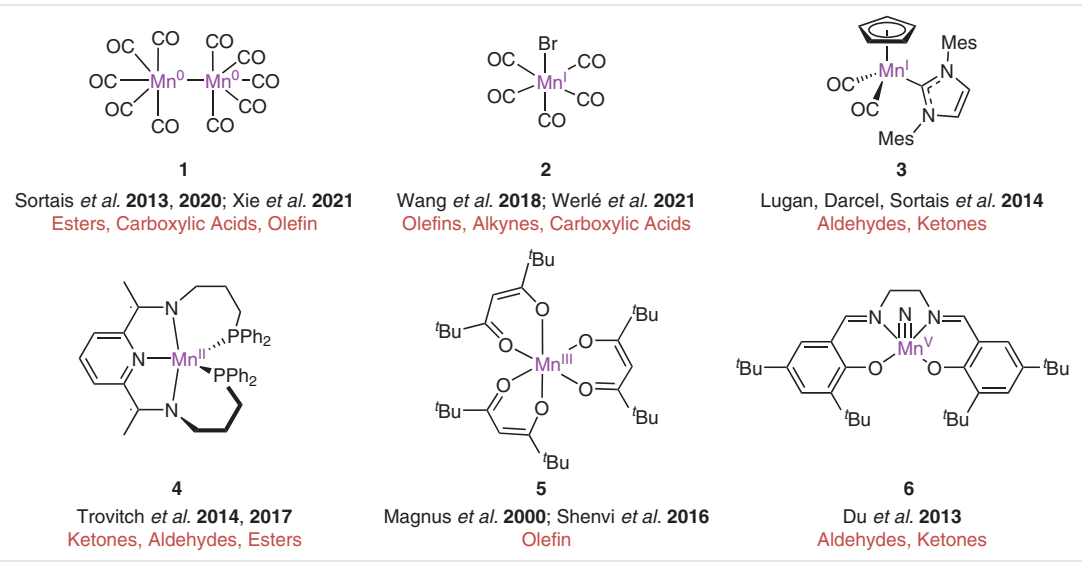

Figure 1 Examples of manganese-based hydrosilylation pre-catalysts in various oxidation states 
showed that other non-conjugated olefins could also be reduced. In 2017, Thomas showed that an ${ }^{\mathrm{E}} \mathrm{BIPMnBr}_{2}$ catalyst (7, BIP = bis(imino)pyridine), similarly to equivalent iron and cobalt complexes, could be used to hydrosilylate and hydroborate terminal alkenes when in the presence of the highly important co-catalyst $\mathrm{NaO}^{t} \mathrm{Bu}$ (Figure 2) ${ }^{35}$ In 2018, the group published a separate hydrosilylation study using $\mathrm{NaO}{ }^{t} \mathrm{Bu}$ and complex 7 with a different Ar group. ${ }^{36} \mathrm{~A}$ fast and selective reduction of alkenes to their linear organosilanes was presented: $25{ }^{\circ} \mathrm{C}$ and 4 hours sufficed for high yields. Trovitch followed this discovery with complex $\mathbf{8}$, which could perform the same transformation. ${ }^{37}$ Wang and Yang, on the other hand, used a commercially available $\operatorname{Mn}(\mathrm{I})$ compound, $\operatorname{MnBr}(\mathrm{CO})_{5}$ (2), to also reduce aliphatic alkenes to linear organosilanes. ${ }^{38}$ Perhaps surprisingly, without the use of specialized ligands, Wang could perform the reduction under only slightly more reactive conditions, $60{ }^{\circ} \mathrm{C}$ and 4 hours. Later, they showed that alkynes could be reduced to vinylsilanes. Three different systems have been developed: firstly, $E$-vinylsilanes were observed in good selectivity (40:1) using 2 and $\mathrm{AsPh}_{3}$, as a ligand, at $150{ }^{\circ} \mathrm{C} ; 3^{39}$ $Z$-vinylsilanes were formed when using $\mathrm{Mn}_{2}(\mathrm{CO})_{10}$ in the presence of dilauroyl peroxide as an additive; ${ }^{39}$ and finally, even higher selectivity towards the $Z$-vinylsilane was detected by the group of Zhang when using $\mathrm{Mn}_{2}(\mathrm{CO})_{10}$ in the presence of blue light (Figure 2B). ${ }^{40}$ Recently, Xie et al. used the same $\mathrm{Mn}_{2}(\mathrm{CO})_{10}$ pre-catalyst in the presence of JackiePhos $(\mathbf{9})$ to give linear organosilanes from alkenes. ${ }^{30}$

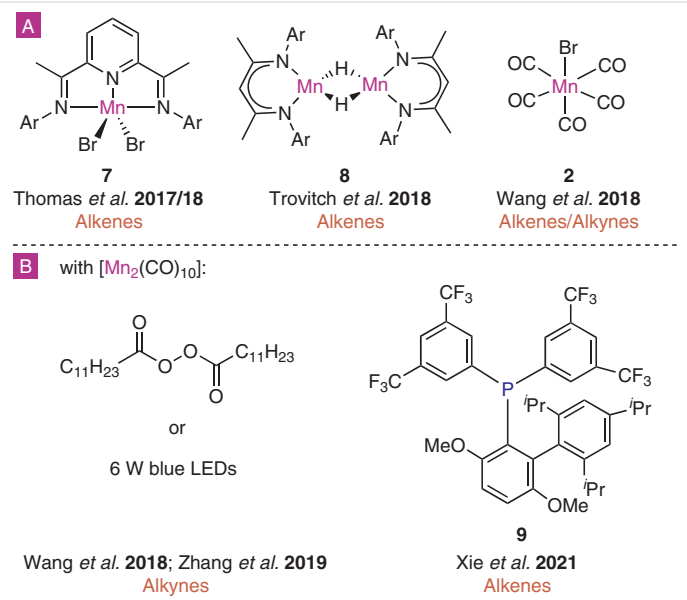

Figure $2 C-C \pi$-bond reduction using silanes and a manganese catalyst: $\mathrm{A}$. $\mathrm{Mn}(\mathrm{II})$ and $\mathrm{Mn}(\mathrm{I})$ complexes; B. Ligands/additives used in addition to the $\mathrm{Mn}(0)$ pre-catalyst $\mathrm{Mn}_{2}(\mathrm{CO})_{10}$

Carbonyl hydrosilylation using a manganese catalyst, initiated by Cutler, was continued by Chung and co-workers in $2000 .{ }^{41}$ The first arene-containing cationic $\mathrm{Mn}(\mathrm{I})$ carbonyl complex, (arene) $\mathrm{Mn}(\mathrm{CO})_{3}{ }^{+}$, was synthesized to reduce several ketones at room temperature using dimethylphenylsilane. Particularly, non-bulky, electron-rich ketones gave high yields in short reaction times. Ring slippage $\left(\eta^{6} \rightarrow\right.$ $\eta^{4}$ ) of the naphthalene coordinated to the metal was attributed to the unique ability of the catalyst. Further developments in $\mathrm{Mn}(\mathrm{I})$ catalysts for the hydrosilylation of carbonyl groups were presented by a collaboration between the group of Lugan and Sortais. ${ }^{25 a}$ The reduction of a range of aldehydes and ketones to alcohols gave high yields in an average of 1-4 hours at room temperature in the presence of $250 \mathrm{~nm}$ light and catalyst 3 (Figure 1). Mechanistic experiments suggest that the photochemical dissociation of the final carbonyl ligand is most likely only possible from a $\mathrm{Mn}(\mathrm{III})$ intermediate, following oxidative addition into the $\mathrm{Si}-\mathrm{H} \sigma$-bond. ${ }^{25 b}$ With the majority of carbonyl systems focusing on low-valent $\mathrm{Mn}(\mathrm{I})$, Du et al. used a high oxidation state $\mathrm{Mn}(\mathrm{V})$ salen complex 6 (Figure 1) to reduce ketones and aldehydes in high yields and at low catalyst loading $(0.5$ mol\%). ${ }^{24}$ Mechanistic experiments, including a Hammett plot, suggest the reduction of the $\mathrm{d}^{2}$ manganese pre-catalyst to a Mn(III) hydride. This may also account for the short induction period and significantly longer reaction times required at lower temperatures.

In 2014, a significant breakthrough in manganese-catalyzed hydrosilylation was published by the group of Trovitch. ${ }^{31}$ Complex 4 (Figure 3 ) is formally neutral bearing the redox-active PDI (pyridinediimine) dianion ligand with a low-valent $\mathrm{Mn}(\mathrm{II})$ center. The catalyst exhibited a TOF (turnover frequency) of $76,800 \mathrm{~h}^{-1}$ and high performance at catalyst loadings as low as $0.01 \mathrm{~mol} \%$ for the reduction of ketones. Ester hydrosilylation was also possible for small, less sterically hindered esters; extremely long reaction times of 10 days were required with increased steric bulk. Developments published later (2017), showed that aldehydes were reduced at an even faster rate (TOF $=4900 \mathrm{~min}^{-1}$ ) than ketones and that catalyst $\mathbf{4}$ could perform the formate dihydrosilylation with a TOF of $330 \mathrm{~min}^{-1} .{ }^{42}$ Catalyst $\mathbf{4}$ is currently available to buy from many commercial chemical vendors. Mechanistic studies suggest a modified Ojima mechanistic cycle where the redox-active ligand assistance maintains a $\mathrm{Mn}(\mathrm{II})$ metal center throughout the reaction. Interestingly, an alternative redox-innocent pentacoordinate complex 10, also synthesized by the group, gave TOF values of $2475 \mathrm{~min}^{-1}$ for benzaldehyde hydrosilylation, only half that of complex $\mathbf{4}$ and a very competitive rate in comparison to other metal catalysts. ${ }^{43}$ The group also synthesized $\mathrm{Mn}(\mathrm{I})$ dimer 12 and $\mathrm{Mn}(\mathrm{III})$ hydride 11 supporting the same ligand backbone. The $\mathrm{Mn}(\mathrm{I})$ dimer showed a similar TOF for benzaldehyde reduction in comparison to complex 4, but the TOF for formate dihydrosilylation was lower on a per manganese basis. ${ }^{44}$ The $\mathrm{Mn}(\mathrm{III})$ hydride catalyst 11 showed poor performance in the hydrosilylation of carbonyls; however, it matched the performance of the leading complex 4 in the reduction of formates and showed even more outstanding performance in the reduction of ethyl acetate. ${ }^{42}$ KIE (kinetic isotope effect) differences between complexes $\mathbf{4}$ and $\mathbf{1 1}$ indicate that the hydrosilylation reactions go through competing mechanisms. In 2017, Huang 
and co-workers reported a similar, but chiral tridentate ligand coordinated to $\mathrm{Mn}(\mathrm{II})$ (13) to reduce ketones to secondary alcohols in high enantiomeric excess. ${ }^{45}$ Catalyst activation using $\mathrm{NaBEt}_{3} \mathrm{H}$ ( $2 \mathrm{~mol} \%$ ) was required. More recently, the group of Royo published a $\mathrm{Mn}(\mathrm{I})$ complex with a bisNHC ligand (15) (see Scheme 1A), which was effective in the hydrosilylation of ketones. ${ }^{32}$ Though more promising yields were obtained with phenylsilane, the readily available silane polymethylhydrosiloxane (PMHS) could also afford alcohols in moderate to good yields. Further examples of $\mathrm{Mn}$ (II) hydrosilylation of aldehydes and ketones were presented by the groups of Madrahimov ${ }^{46}$ and Sunada. ${ }^{47}$ The latter managed to utilize TMDS (tetramethyldisiloxane) as the silane source.

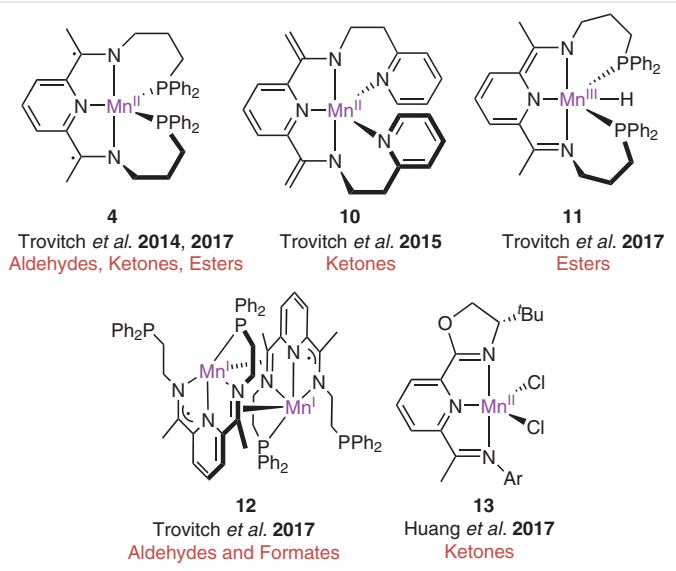

Figure 3 Developments on $\mathrm{Mn}$ (II) complexes initiated by Trovitch in 2014

Apart from the examples of Cutler and Trovitch, not many examples of ester hydrosilylation were published in the literature until recently. Werlé and Leitner used their $\mathrm{Mn}(\mathrm{I})$ triazole catalyst $\mathbf{1 6}$ (Scheme 1 ) to reduce esters to alcohols as the major product instead of ethers like the Cutler group; however, small amounts of ether (10-20\%) could also be detected. ${ }^{48}$ High selectivity for the alcohol product was obtained by using Mn(I) complexes 15 (Royo) and 14 (Bagh), reported in $2020 .{ }^{49}$ The group of Sortais formed silyl acetals, in contrast, by using the readily available $\mathrm{Mn}_{2}(\mathrm{CO})_{10}$ complex under UV light conditions (LED $265 \mathrm{~nm}$ ) (Scheme 1). ${ }^{27 \mathrm{~b}}$ Aldehydes were isolated in high yields following acidic hydrolysis. Sydora, Stradiotto, and Turculet used their catalyst $\mathbf{1 7}$ to reduce a methyl benzoate derivative and methyl heptanoate to their respective alcohols in high yield, although no other examples were given. Instead, the group focused on the, also challenging, hydrosilylation of amides. ${ }^{50}$ With catalyst $\mathbf{1 7}$ ( $2 \mathrm{~mol} \%$ ), a range of tertiary amides were deoxygenatively reduced overnight at room temperature. Only two other minor examples have shown the potential of manganese to reduce amides via a deoxygenative hydrosilylation: work from Fuchikami, using $\mathrm{Mn}_{2}(\mathrm{CO})_{10}$ with a diethylamine additive in thermally activated condi- tions, ${ }^{51}$ and Pannell, using $\mathrm{CpMn}(\mathrm{CO})_{3}$ to reduce DMF and DEF within a mechanistic study. ${ }^{52}$ Nitrile reduction using silanes and a manganese catalyst was also most recently performed by the group of Kundu. ${ }^{53}$

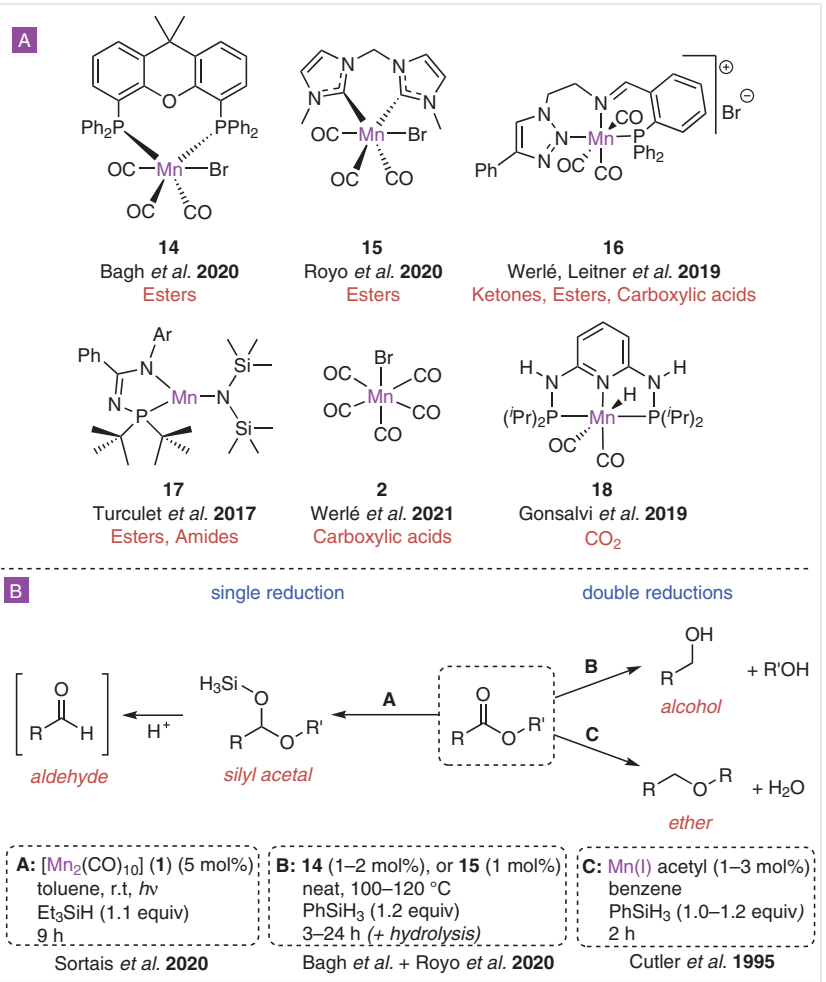

Scheme 1 A. Recent manganese catalysts for more challenging carbonyl reductions using hydrosilanes; B. Hydrosilylation of esters into their different possible products (selected examples are used as conditions)

An important field of manganese hydrosilylation research has been the pursuit of a catalyst that can reduce a range of carboxylic acids since no currently known homogenous manganese catalyst exists for the transfer hydrogenation or hydrogenation of carboxylic acids. The group of Sortais and Darcel used $\mathrm{Mn}_{2}(\mathrm{CO})_{10}$ under photochemical conditions to reduce carboxylic acids to their respective aldehydes after acidic hydrolysis (Scheme 1B). ${ }^{27 a}$ During their silane screening, the alcohol product was also formed as the major product when secondary silanes were used; impressively, this was even the case with cheap and industrially applicable TMDS. However, the strengths or limitations of the system for use in the synthesis of alcohols were not studied in this publication. Though a large scope of aliphatic carboxylic acids was reduced to their respective aldehydes in high yield, benzylic acids could not be reduced with greater than 30\% conversion. In 2019, Werlé and Leitner contributed to this field by reducing a small number of benzylic and aliphatic carboxylic acids to alcohols (using catalyst 16, see Scheme 1). ${ }^{48}$ More recently (2021), Werlé and co-workers developed this work to show that the com- 
mercially available manganese complex $\operatorname{MnBr}(\mathrm{CO})_{5}$ (2) could reduce a large scope of acids to alcohols within 4 hours for most aliphatic acids and 2 hours for aromatic acids. ${ }^{33}$ Separate experiments showed that as low as $0.5 \mathrm{~mol} \%$ catalyst loading could be used at the expense of time to generate equally high yields. A gram-scale reaction performed using only 1.5 equiv. of $\mathrm{PhSiH}_{3}$ was conveniently isolated after a Kugelrohr distillation in 93\% yield. Mechanistic and gas phase analysis suggested the loss of $1 \mathrm{CO}$ molecule with $\eta^{2} \mathrm{Si}-\mathrm{H}$ manganese coordination, where $\mathrm{Mn}(\mathrm{I})$ remains the active oxidation state of the metal throughout the reaction.

Another challenging hydrogenation transformation using a manganese catalysts is the conversion of $\mathrm{CO}_{2}$ to $\mathrm{MeOH}$. Gonsalvi and Kirchner showed that their (PNP) $\mathrm{Mn}(\mathrm{CO})_{2} \mathrm{H}$ catalyst 18 (Scheme 1) could dramatically catalyze the single reduction of carbon dioxide to formate, which requires 24 hours without catalyst, and the triple reduction to methanol, which gave almost quantitative yields at $80{ }^{\circ} \mathrm{C} .{ }^{54} \mathrm{In}$ 2021, Garcia et al. reported using $\operatorname{MnBr}(\mathrm{CO})_{5}$ with $\mathrm{Et}_{3} \mathrm{SiH}$ at mild $\mathrm{CO}_{2}$ pressures ( $<4$ bar) to selectively obtain either the (silyl)formate or bis(silyl)acetal, depending on solvent composition. ${ }^{55}$

\section{Hydroboration}

Manganese-catalyzed hydroboration reactions are not as common historically in comparison to hydrosilylation reactions. In 2016, Zhang and Zheng reported the use of man- ganese catalyst 19 for the chemoselective reduction of ketones over alkenes and the selective Markovnikov hydroboration of styrene derivatives (Scheme 2). ${ }^{56}$ The group utilized a pincer $\mathrm{Mn}$ (II) complex supported by a terpyridine ligand. The hydroboration of aliphatic alkenes gave, with much lower selectivity, the anti-Markovnikov product. Since then, the rapid development of manganese-catalyzed hydroboration has taken place.

\subsection{Catalyst Overview}

The development of both $\mathrm{Mn}(\mathrm{I})$ and $\mathrm{Mn}(\mathrm{II})$ pincer complexes appears to have unleashed the potential of manganese-catalyzed hydroboration. To date, mechanistic investigations have not been able to differentiate a clear difference in mechanism between $\mathrm{Mn}(\mathrm{I})$ and $\mathrm{Mn}(\mathrm{II})$ complexes. However, studies of intermediate manganese complexes by experimental or computational experiments have shown, more often than not, the involvement of a manganese hydride intermediate.

Du's $\mathrm{Mn}(\mathrm{V})$ catalyst 6 (see Figure 1 ) is thought to be reduced to form an active hydride species, a possible Mn(III) hydride, in a similar fashion to the hydrosilylation reactions. ${ }^{57}$ By adding two different boranes, one of which was deuterated, in the presence of the manganese catalyst under standard reaction conditions, no scrambling was observed. On the basis of these findings, it was believed that the manganese hydride acted as a weak Lewis acid to activate HBpin rather than as a direct hydride transferring catalyst. Gade et al. proposed the same Lewis acid activated

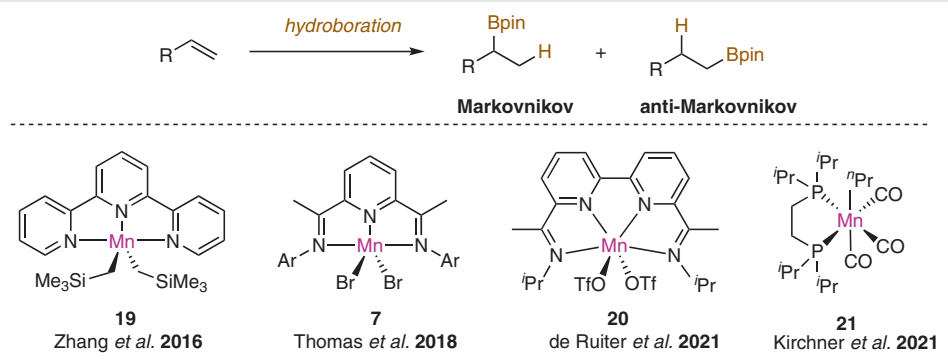

Scheme 2 Hydroboration of terminal alkenes using Mn(II) pincer catalysts (7, $\mathrm{Ar}=$ 2,6-diisopropylbenzene)
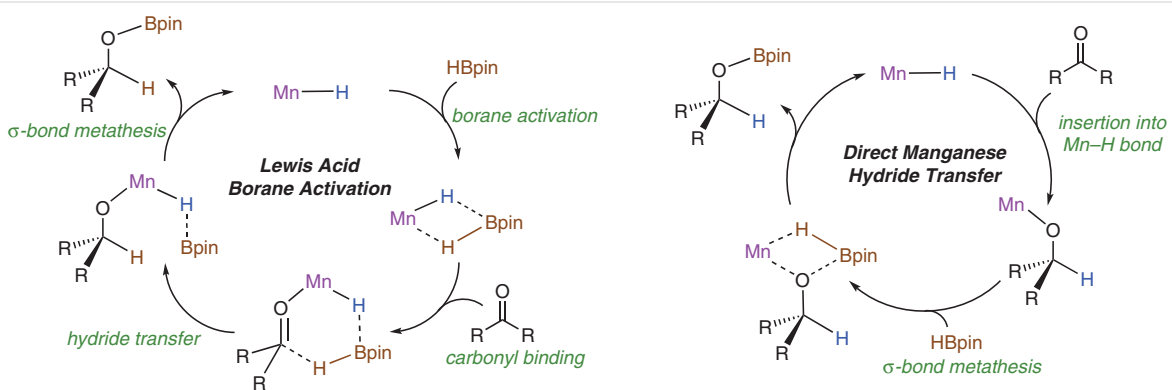

Scheme 3 Simple schematic representation of the two ways manganese hydrides can catalyze a hydroboration reaction (for the purposes of this simplification, a ketone substrate is shown) 
pathway for their asymmetric $\mathrm{Mn}(\mathrm{II})$ catalyst. ${ }^{58}$ In contrast, the proposed mechanistic cycles for $\mathrm{Mn}(\mathrm{I})$ catalysts typically follow a direct manganese hydride transfer, as seen in the examples by Maji ${ }^{59}$ and Leitner. ${ }^{60}$ The two different manganese hydride pathways are shown in generic form in Scheme 3. Also, when Trovitch and Baik performed computational calculations of their $\mathrm{Mn}$ (II) catalyzed dihydroboration of nitriles, direct insertion of the substrate into the $\mathrm{Mn}-\mathrm{H}$ bond was in plausible agreement with experimental observations. The manganese hydride could be re-formed via a $\sigma$-bond metathesis. ${ }^{61}$ Leitner showed that a welldesigned ligand could assist B-H activation and, therefore, the regeneration of the manganese hydride. ${ }^{60}$

\subsection{Development of Manganese-Catalyzed Hydro- boration Reactions}

Following the initial work by Zhang, the groups of Thomas (2018) ${ }^{36}$ and de Ruiter (2021) ${ }^{62}$ used their Mn(II) catalysts $\mathbf{7}$ and $\mathbf{2 0}$, respectively, to form the linear organoboronate compounds from both aromatic and aliphatic alkenes. In 2020, the group of Rueping used a bis(imino)pyridine (BIP) ligand - also used by Thomas (catalyst 7 , Scheme 2) - to synthesize a (BIP) $\mathrm{MnCl}_{2}$ catalyst for the single reduction of propargylic alcohols and amines as well as internal alkynes. ${ }^{63}$ This afforded highly valuable, functionalized alkenes, with a possible application as substrates for cross-coupling reactions. Even more recently, the group of Kirchner first used their Mn(I) catalyst 21 (Scheme 2) with HBPin to also reduce terminal alkenes into the respective linear organoborates at low catalyst loadings $(0.25 \mathrm{~mol} \%){ }^{64}$ Interestingly, terminal alkynes could be reduced with unique selectivity, the trans-1,2-diborated product isolated as the major product (Scheme 4). Although the highest observed selectivity was only $55 \%$ and products could only be isolated up to $44 \%$ yield, the reaction is unprecedented in transition-metal catalysis and affords a valuable building block in organic chemistry. Further experiments and DFT calculations propose an acceptorless pathway with the release of dihydrogen within the mechanism. ${ }^{64}$

Hydroboration of carbonyl compounds also affords chemically valuable products, often in the form of alcohols, after silica-activated hydrolysis. By using specifically designed pincer ligands, the groups of Zhang and Zheng,,56 Du, ${ }^{57}$ Gonsalvi and Kirchner, ${ }^{65}$ Maji, ${ }^{59}$ and Leitner ${ }^{60}$ could all form alcohols from different substrates using pinacolborane as the reduction source (Figure 4). Most examples showed high catalytic activity at low catalyst loadings ( $<1$ mol\%) and low temperatures, with exceptions being the work of Leitner, which required elevated temperatures (90$11{ }^{\circ} \mathrm{C}$ ) for the reduction of substrates more challenging to reduce. Trovitch and Baik synthesized diborylamines, useful for cross-coupling chemistry, from nitriles via double hydroboration. ${ }^{61}$ This reduction also needed higher temperatures of around $80^{\circ} \mathrm{C}$. The potential for asymmetric hydroboration reductions using chiral pincer ligands was realized by Gade et al. ${ }^{58}$ Their catalyst $\mathbf{2 4}$ (2.5 mol\%) reduced ketones to their respective secondary alcohols in high enantiomeric excesses.

More recently, when the de Ruiter group investigated their manganese catalyst 20 (see Scheme 2), they discovered that the simple manganese triflate catalyst $\mathrm{Mn}(\mathrm{OTf})_{2}\left(\mathrm{CH}_{3} \mathrm{CN}\right)_{2}(\mathbf{2 5}$; Scheme 5$)$ gave comparative activity for the reduction of esters, carbonates, and nitriles. ${ }^{66}$ Jacobi von Wangelin et al. also showed that their simple $\mathrm{Mn}(\mathrm{hmds})_{2}$ catalyst (26; hmds = hexamethyldisilazane) reduces an extensive array of organic compounds (esters, amides, pyridines, carbonates, polycarbonates, diimides, and carbon dioxide) via hydroboration (Scheme 5). ${ }^{67}$ Also, in this case, a manganese hydride was detected: upon the reaction of the pre-catalyst with pinacolborane, a cluster of $\mathrm{MnH}(\mathrm{hmds})_{6}$ was formed, which could stoichiometrically reduce benzaldehyde via direct hydride transfer from the metal.

Alternative manganese-based systems have also recently been developed in contrast to small monomeric molecular catalysts. Zheng and Zhang used a terpyridine-based $\mathrm{Mn}(\mathrm{II})$ coordination polymer as a pre-catalyst for the reduction of a range of carbonyls as well as styrene derivatives via

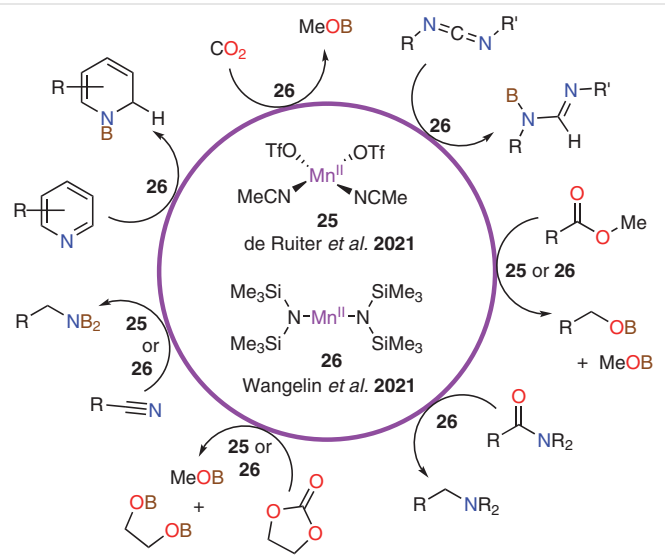

Scheme 5 Simple $\mathrm{Mn}(\mathrm{II})$ catalysts for the hydroboration of $\mathrm{C}-\mathrm{X}$ $\pi$-bonds ('B' = BPin)

$$
\begin{aligned}
& \mathrm{Ph}=\frac{21(0.5 \mathrm{~mol} \%), \mathrm{HBPin}(1.5 \text { equiv) }}{\mathrm{THF}, 70^{\circ} \mathrm{C}, 24 \mathrm{~h}}+\mathrm{Ph}_{\mathrm{BPin}}^{\mathrm{BPin}}+\mathrm{Ph}_{\mathrm{BPin}}+\overbrace{\mathrm{BPin}}+\overbrace{\mathrm{Ph}}^{\mathrm{BPin}} \\
& \begin{array}{llllll}
97 \% \text { conversion } & \text { Selectivity: } & 48 \% & 39 \% & 7 \% & 6 \%
\end{array}
\end{aligned}
$$

Scheme 4 Reduction of terminal alkynes using Mn(I) catalyst 21 (fully drawn in Scheme 2) 

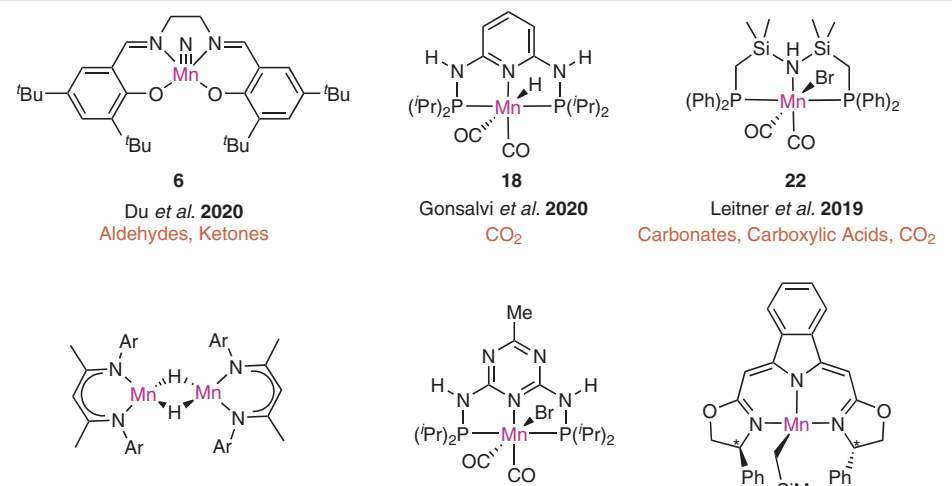

$$
\begin{gathered}
8 \\
\text { Trovitch et al. } 2020 \\
\text { Nitrile }
\end{gathered}
$$

23

Maji et al. 2019 Carboxylic Acids

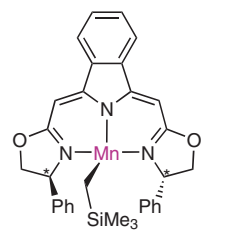

24

Gade et al. 2017

Figure 4 Hydroboration of polarized C-X $\pi$-bonds using pinacolborane and specifically designed pincer catalysts; substrates reduced are written in red $(8, A r=2,6 \text {-diisopropylbenzene })^{61}$

both hydrosilylation and hydroboration..$^{68}$ Another example by Copéret and co-workers showed that manganese could be used with surface organometallic chemistry (SOMC) without an organic ligand; aldehydes and ketones could be reduced with comparative performance. ${ }^{69}$

\section{Hydrogenation}

The earliest examples of manganese-catalyzed hydrogenation reactions were published in 2016, starting with the work of Beller and co-workers. ${ }^{70}$ They used their Mn(I) catalyst $\mathbf{2 7}$ (Figure 5) to reduce nitriles, ketones, and aldehydes under a $\mathrm{H}_{2}$ pressure atmosphere. Soon thereafter, this group added to this discovery by using the slightly different PNP catalyst $\mathbf{2 8}$ to reduce esters. ${ }^{71}$ Interestingly, catalyst $\mathbf{2 8}$ exhibits facial coordination, which appears to be the kinetic product, instead of the more commonly found meridional coordination. By monitoring the reaction in comparison to mer-28, it was hypothesized that the coordination of the pre-catalyst had no impact on the catalytic activity and that a common active species would be present in the mechanistic cycle. That same year, Kempe ${ }^{72}$ and Milstein ${ }^{73}$ used their own $\mathrm{Mn}(\mathrm{I})$ complexes $\mathbf{2 9}$ and 30, respectively, to re- duce ketones and esters, respectively (summarized in Figure 5). The rapid development in catalytic design and substrate reduction that followed is outlined below.

\subsection{Catalyst Overview}

From all the possible oxidation states of manganese observed to date, only manganese(I) species have been used as hydrogen transfer catalysts in hydrogenation reactions. The next most important catalytic design feature allowing catalytic hydrogenation to take place has been the ligand framework. MLC has been of utmost importance for activating hydrogen, with multiple different systems developed (Figure 6). 'Type A' catalysts can undergo deprotonation on the ligand backbone; this generates an important change in the first coordination sphere of the metal, as the N-heteroaromatic ring loses its aromaticity and allows the coordinating nitrogen atom to act as an amide donor. 'Types B-D' catalysts all contain an $\mathrm{M} / \mathrm{N}-\mathrm{H}$ system in the complex, an important feature shown to improve the activity of noblemetal complexes that are commonly associated with the work of the Noyori group. Also, here, deprotonation/reprotonation within the catalytic cycle is possible; however, it should be noted that, through studies with the original Noyori catalysts, several proposed mechanisms of $\mathrm{N}-\mathrm{H}$ in-

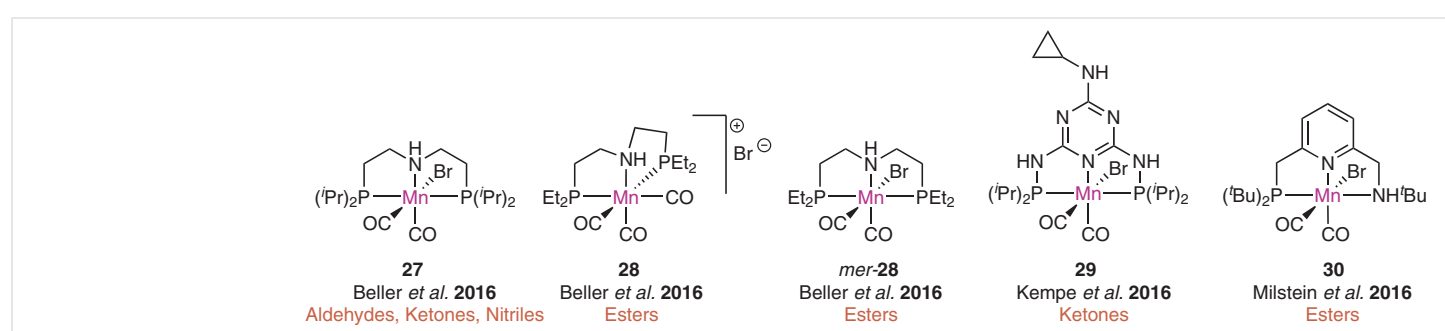

Figure 5 First examples of manganese-catalyzed hydrogenation were published by the groups of Beller, Kempe, and Milstein, all in 2016 


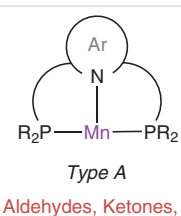

Esters, $\mathrm{CO}_{2}$

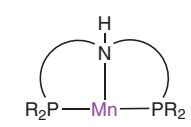

Type B

Aldehydes, Ketones, Nitriles,

Esters, Cyclic Carbonates, $\mathrm{N}$-Heterocycles, $\mathrm{CO}_{2}, \mathrm{CO}$

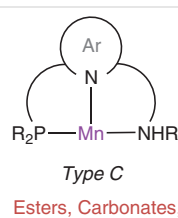

sters, Carbonates,

Ketoamides

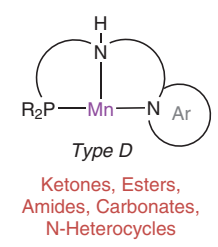

Figure 6 A breakdown of the basic ligand structures used for manganese-catalyzed hydrogenation reactions

volvement exist, discussed elsewhere. ${ }^{74}$ For the purpose of this concise review, we will simply refer to these systems as MLC systems, as, with all mechanisms, the ligand and metal play integral roles in the activation of substrates. ${ }^{12 a}$ These four catalytic systems have been the most common in the manganese hydrogenation literature to date. The complexes commonly form a classical pincer coordination geometry; however, facial coordination has also been observed in several active catalysts (e.g., complex 28, Figure 5). 'Type E' catalysts have been used by the groups of Garcia and Kirchner for manganese-based hydrogenation reactions; it shows an alternative system where the coordinating solvent or substrate (symbolized by $\mathrm{X}$ in Figure 6 ) assists the metal in the activation of hydrogen (vide infra). There are a couple of noteworthy exceptions to these five systems: Beller et al.'s use of $\mathrm{MnBr}(\mathrm{CO})_{5}$ for the hydrogenation of quinolines, ${ }^{75} \mathrm{Hu}$ et al.'s biomimetic manganese catalyst $\mathbf{3 6}$ (Scheme 6A; see below) for aldehyde, ketone, and imine hydrogenation, ${ }^{76}$ and Khusnutdinova and Nervi's use of hydroxy deprotonation on their MLC system 46 (Scheme 8C; see below) for the single reduction of $\mathrm{CO}_{2} \cdot{ }^{77}$

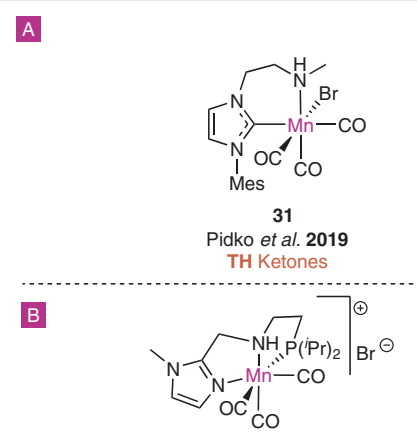

33

Easier Hydride Transfer

\begin{tabular}{|c|c|}
\hline Easier Hydride Transfer & Easier Hydrogen Activation \\
\hline \multicolumn{2}{|c|}{ Increased electron-donating and reduced steric bulk ligands } \\
\hline \multicolumn{2}{|l|}{ Liu et al. 2019} \\
\hline \multicolumn{2}{|c|}{ Improved activity for hydrogenation of esters, amides and quinolines } \\
\hline Beller et al. 2019; Leitner et al. & 021 \\
\hline
\end{tabular}

Figure 7 Overview of two important features of ligand design that affect the hydrogenation of manganese-catalyzed reactions: A. Pidko group bidentate 31 and tridentate 32 complexes, which show different levels of thermal stability; B. Comparison between PNP ('type B') and NNP ('type D') complexes for the hydrogenation of organic substrates (majority of the comparison is summarized from Liu et al. ${ }^{78}$ )
Understanding the mechanistic effect of the ligand system has become an important focus of research for the development of novel, highly active hydrogenation catalysts. In a recent publication from the group of Filonenko and Pidko, the high-performance $\left(\right.$ TOF $=41,000 \mathrm{~h}^{-1}$, TON $=$ 200,000 ) and thermally stable (at $120^{\circ} \mathrm{C}$ ) Mn(I) catalyst 32 (Figure 7A) was used for a range of carbonyl hydrogenation reactions. ${ }^{79}$ It highlighted the important effect of the 'third arm', in this case the phosphine, for stabilizing the tridentate NHC-NP complex 32, since the equivalent bidentate complex 31 (Figure 7A), also by Pidko, underwent rapid thermal decomposition at $>75{ }^{\circ} \mathrm{C} .{ }^{80}$

The effect of changing the electronic or steric environment of the complex by changing the substituents on similar PNP ('type B') and NNP ('type D') complexes was studied by Lan and Liu. ${ }^{78}$ They observed clear differences between the two types, with higher activity for more electron-rich and less bulky NNP complexes compared to similar PNP derivatives (Figure 7B). This discovery is in line with the development made by Pidko and co-workers, whose highly active complex 32 contained an electron-donating and planar NHC group. With this rationale, Lan and Liu used complex 33, previously used by Beller for the hydrogenation of amides, ${ }^{81}$ for the first hydrogenation of quinolines by a manganese catalyst. The catalyst outperformed similar less electron-donating and bulkier PNP complexes as expected. Unexpected are the catalytic activity differences between complexes 33 with $\mathbf{2 7}$, which have previously been reported in screening reactions by the groups of Beller ${ }^{82}$ and Leitner. ${ }^{83}$ In the one-pot reduction of carbon monoxide assisted by alcohols from the Leitner group, complex 33 afford only minor amounts of formate and undetectable amounts of $\mathrm{MeOH}$. Under the same conditions, catalyst 27 produced almost $3 \mathrm{mmol}$ of $\mathrm{MeOH}$ with $>99 \%$ selectivity. When the group of Beller tested the formamide reduction (for amine-assisted CO hydrogenation), low amounts of $\mathrm{MeOH}$ and amine were detected with catalyst 33 in comparison to 27. Likewise, for ethylene carbonate reduction, catalyst 33 afforded similarly low yields of product in comparison to other PNP 'type A' catalysts, whereas the PNP 'type B' catalyst 27 gave between 8-12 times higher TON for $\mathrm{MeOH}$ and ethylene glycol (Figure 7B). The computational calculations performed by the group of Lan and $\mathrm{Liu}^{78}$ suggest that the less electron-donating and bulkier PNP complexes favor rapid activation of hydrogen to form the 
manganese hydride via a lower activation barrier and more stable manganese hydride. In contrast, the NNP complexes have a lower activation barrier for the hydride transfer from the metal to the carbonyl (in silico calculations used an amide as the model carbonyl). The ability of the ligand to facilitate different steps in the mechanism gives an increased insight into the challenges in predicting improved novel catalysts for hydrogenation transformations.

\subsection{Development of Manganese-Catalyzed Hydro- genation Reactions}

Between the early developments of Beller and Kempe in 2016 and the most recent low catalyst loading publication from Filonenko and Pidko (2021), there have been several noteworthy additions to the hydrogenation of carbonyl groups literature. Following the use of a tridentate 'type B' catalyst by Sortais and co-workers, ${ }^{84}$ the same group developed a series of bidentate manganese complexes in 20182019 that only required $50-60{ }^{\circ} \mathrm{C}$ to reduce a range of ketones in high yields (Scheme 6). ${ }^{85}$ The most recent of the publications used a phosphonium ylide intermediate to activate hydrogen via a non-classical MLC pathway. ${ }^{86}$ The group of Kirchner performed highly selective hydrogenation of aldehydes; catalyst $\mathbf{1 8}$ reduced aldehydes, while ketones, esters, alkynes, nitriles, heteroaromatics, $\alpha, \beta$-unsaturated bonds, and alkenes were all not hydrogenated (Scheme 6). ${ }^{87}$ In 2019, Hu and co-workers used a completely different style of catalyst (36) based on a biomimetic model to reduce a range of carbonyls (Scheme 6). ${ }^{76}$ This example, however, did not exhibit any preferable activity in carbonyl reduction, still requiring pressures of 50 bar (as in the work of Sortais). In 2021, the group of Kirchner also performed the hydrogenation of ketones and $\alpha, \beta$-unsaturated ketones using their (dippe) $\operatorname{Mn}{ }^{\mathrm{n}} \operatorname{Pr}(\mathrm{CO})_{3}$ catalyst [21, dippe $=1,2$-bis (diisopropylphosphino)ethane $]$ under relatively mild conditions: 10 bar $\mathrm{H}_{2}$ and $60^{\circ} \mathrm{C} .88 \mathrm{~A}$ well-known migratory insertion reaction followed by hydrogenolysis of the acyl intermediate was used to activate the manganese alkyl complex and form the active manganese hydride (Scheme 6B). The unusual 'type E' ligand framework (Figure 6 ), without the possibility to perform MLC through the permanent ligand framework, was able to activate dihydrogen with an inner-sphere substrate assistance (Scheme 6C).

After original developments from Beller and Milstein in ester hydrogenation, the group of Pidko formed a bidentate manganese complex that could also reduce esters. ${ }^{89}$ The catalyst could reduce a range of esters in high yields at similar temperatures to the previous publications; however, slightly elevated hydrogen pressures and significantly higher base loading were required. The same group later contributed computational insights into the reaction. ${ }^{90}$ Clarke and co-workers also made an important contribution to the field with their complex 37 (seen in Figure 8); this catalyst could reduce esters at particularly low catalyst loadings and

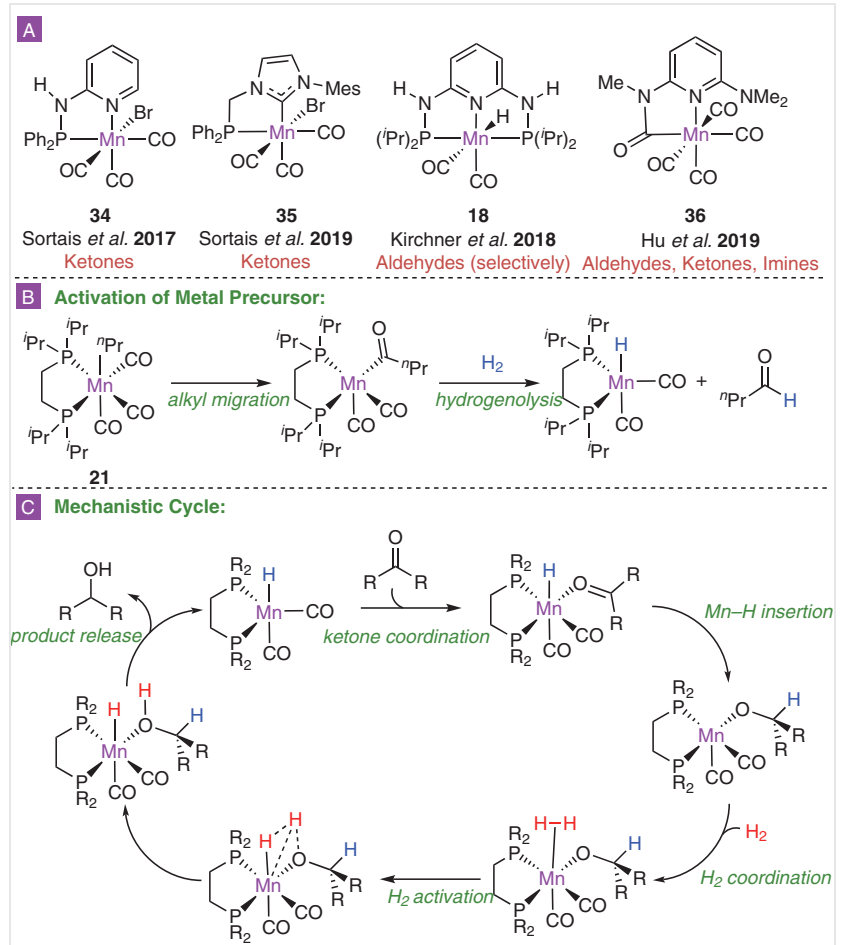

Scheme 6 Manganese catalysts for carbonyl hydrogenation: A. Catalyst examples from the literature; B. Activation of Kirchner's hydrogenation catalyst 21; C. Suggested mechanistic cycle of the Mn(I)dippe ('type E', Figure 6) catalyst used by Kirchner and Garcia

reduce ketone asymmetrically to give secondary alcohols in high yield with enantiomeric excesses up to $97 \%{ }^{91}$ Further developments from the group also include using the racemic version of $\mathbf{3 7}$ to reduce enantioenriched $\alpha$-chiral esters without loss of stereochemistry. ${ }^{92}$ The groups of Beller, ${ }^{93}$ Zhong, ${ }^{94}$ Wen and Zhang, ${ }^{95}$ Morris, ${ }^{96}$ and Wang, Han and Ding ${ }^{97}$ have all also added to the field of asymmetric ketone hydrogenation using enantiomerically enriched chiral manganese complexes 38-42 (Figure 8).

Nitrile hydrogenation has only been replicated, since Beller's original 2016 publication (with catalyst 27, Figure $5)$, using diphosphine bidentate ligands on a $\mathrm{Mn}(\mathrm{I})$ center ('type E'). ${ }^{99}$ The best conditions for the reduction of a range of benzonitriles were obtained by Garcia et al., using low pressure (6.9 bar) and $<100{ }^{\circ} \mathrm{C}$ for 15 minutes. ${ }^{99 a}$ The (dippe)MnOTf(CO) $)_{3}$ catalyst, expectedly, follows a similar mechanistic cycle as the other 'type E' catalysts (Scheme $6 C)$. Imine reduction, traditionally one of the more facile functional group reductions, was performed by the group of Sortais using their simple bidentate catalyst 34, also used to reduce ketones (Scheme 6A). Subsequently, the group deployed this finding in the reductive amination of aldehydes and amines, using $\mathrm{H}_{2}$ as the reduction source: the reaction was performed in a stepwise process with the crude imine hydrogenated to prevent the faster hydrogenation of aldehyde over the condensation reaction. ${ }^{100}$ The reduction of 

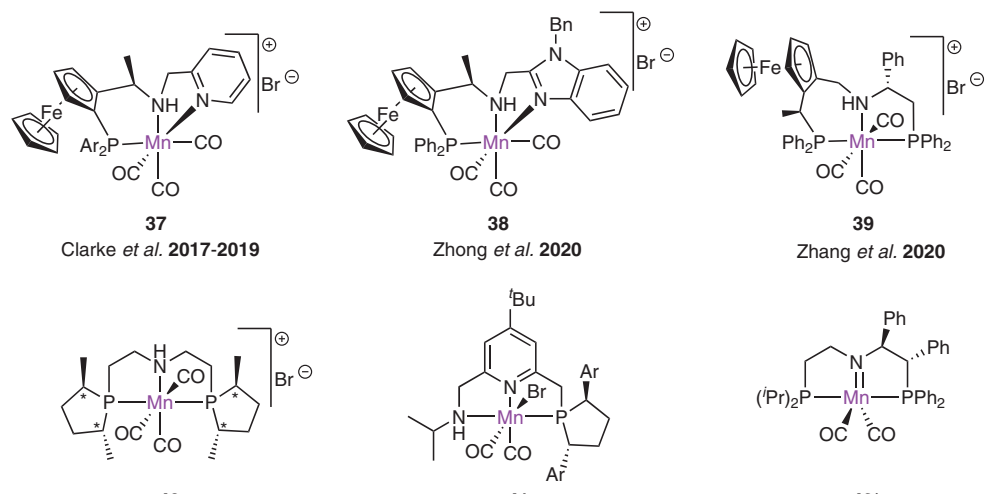

41

Beller et al. 2017

Ding et al. 2019, 2020

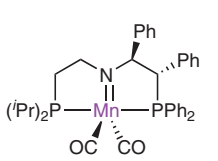

$42^{*}$ Morris et al. 2021

Figure 8 Manganese-based catalysts for the asymmetric hydrogenation of ketones ( $\mathbf{3 7}, \mathrm{Ar}=\mathrm{Ph} ;{ }^{91,98} \mathbf{4 1}$, variations of $\operatorname{Ar}$ were $^{\text {used }}{ }^{97}$ )

imines was later (2019) also performed by Kempe using a variation on their triazine-based catalyst 29 (see Figure 5). ${ }^{101}$ As an extension to the work started in 2016 on ketone reduction, thorough mechanistic insights into the role of the doubly deprotonated manganese hydride $[\mathrm{Mn}-\mathrm{H}] \mathrm{K}_{2}$ species and the imine hydrogenation mechanism was presented. In 2020, Mao and Wang reported the use of the ligand- and base-free hydrogenation system with $\mathrm{MnBr}(\mathrm{CO})_{5},{ }^{102}$ developed earlier that year by Beller et al., for hydrogenation of imines and quinolines. The group of Beller showed that at 15 bar $\mathrm{H}_{2}$ and at $45^{\circ} \mathrm{C}$, the presence of only $\mathrm{MnBr}(\mathrm{CO})_{5}$ was sufficient to hydrogenate quinolines in high yield (Scheme 7$).{ }^{75}$ Thorough mechanistic investigations led to the understanding that several $\mathrm{Mn}$ (II) species were generated during the reaction via disproportionation; however, neither of the major isolated Mn(II) species was involved in the hydrogen transfer. Instead, the species were shown to act as Lewis acids in the activation of the quinoline with the $\mathrm{Mn}(\mathrm{I})$ intermediate $\mathrm{MnH}(\mathrm{CO})_{5}$ identified as an active hydride transfer compound. MLC manganese complexes have also been used to hydrogenate quinolines and N-heteroaromatic molecules: the Liu group's 33 (vide supra, Figure 7), ${ }^{78}$ then the group of Rueping with a 'type B' catalyst, ${ }^{103}$ and finally asymmetric quinoline hydrogenation was performed by Lan and Liu. ${ }^{104}$ Despite the use of a base and a specialized ligand system, none of the three systems had any significant improvements in temperature, $\mathrm{H}_{2}$ pressure, or time.

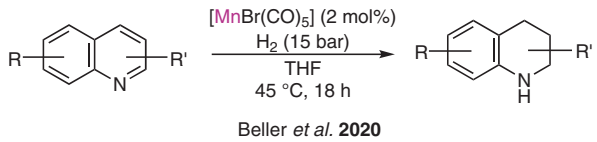

Scheme 7 Hydrogenation of quinolines using the commercially available $\operatorname{MnBr}(\mathrm{CO})_{5}$, presented by Beller et al.
In 2017, Beller and co-workers reported the use of complex 33 to reduce amides to amines and alcohols (Scheme 8). ${ }^{81}$ A year later, the group of Milstein reported the reduction of amides via a deoxygenative hydrogenation (43, Scheme 8). ${ }^{105}$ In this case, a Lewis acid was required to allow the reaction to occur, most probably due to its function in assisting dehydration. Following this work, three groups (Milstein, Rueping, Leitner), in the space of two months, all independently, published reports of carbonate and cyclic carbonate reduction, to afford a pair of alcohols, or a diol, and methanol. ${ }^{83 a, 106}$ Summarized in Scheme 8B, the groups of Leitner (27) and Milstein (30) used lower hydrogen pressures, while the group of Rueping (44) used $1 \mathrm{~mol} \%$ of catalyst to produce diols in more than $90 \%$ yields consistently. The even more challenging carbamates and urea functional groups were hydrogenated by Milstein and co-workers using a similar, but a little more electron-donating and less sterically bulky, pincer backbone (45). ${ }^{107}$ The same catalyst also performed best in the screening of catalysts performed by their group for the hydrogenation of cyclic imides (published 2020). ${ }^{108}$

In 2017, Kirchner, Gonsalvi, and co-workers, published the single reduction of carbon dioxide to formate by using manganese catalyst 18 (Scheme 8C). ${ }^{109}$ By using stoichiometric amounts of $\mathrm{DBU}, \mathrm{CO}_{2}$ was reduced to the $\mathrm{DBUH}^{+} \mathrm{HCOO}^{-}$product by a 'type A' manganese catalyst (20 $\mathrm{ppm}$ ) in the presence of LiOTf (10 mol\%) as Lewis acid. The formate species was isolated in $63 \%$ yield (TON $=31,600$ ). Khusnutdinova and Nervi went on to reduce carbon dioxide to formate using a similar $\mathrm{Mn}(\mathrm{I})$ catalyst/DBU system. ${ }^{77}$ Interestingly, an $\mathrm{OH}$ group on their catalyst $\mathbf{4 6}$, in contrast to the majority of $\mathrm{NH}$ group systems, was deprotonated in a bio-inspired fashion to allow for MLC to occur (Scheme 8C). In addition, $\mathrm{CO}_{2}$ activation by different MLC manganese catalysts was studied by the Milstein group, ${ }^{110}$ and, more recently, by Kirchner and Gonsalvi, who used catalyst 21 to synthesize the formate-DBU aggregate from $\mathrm{CO}_{2}$, albeit in 

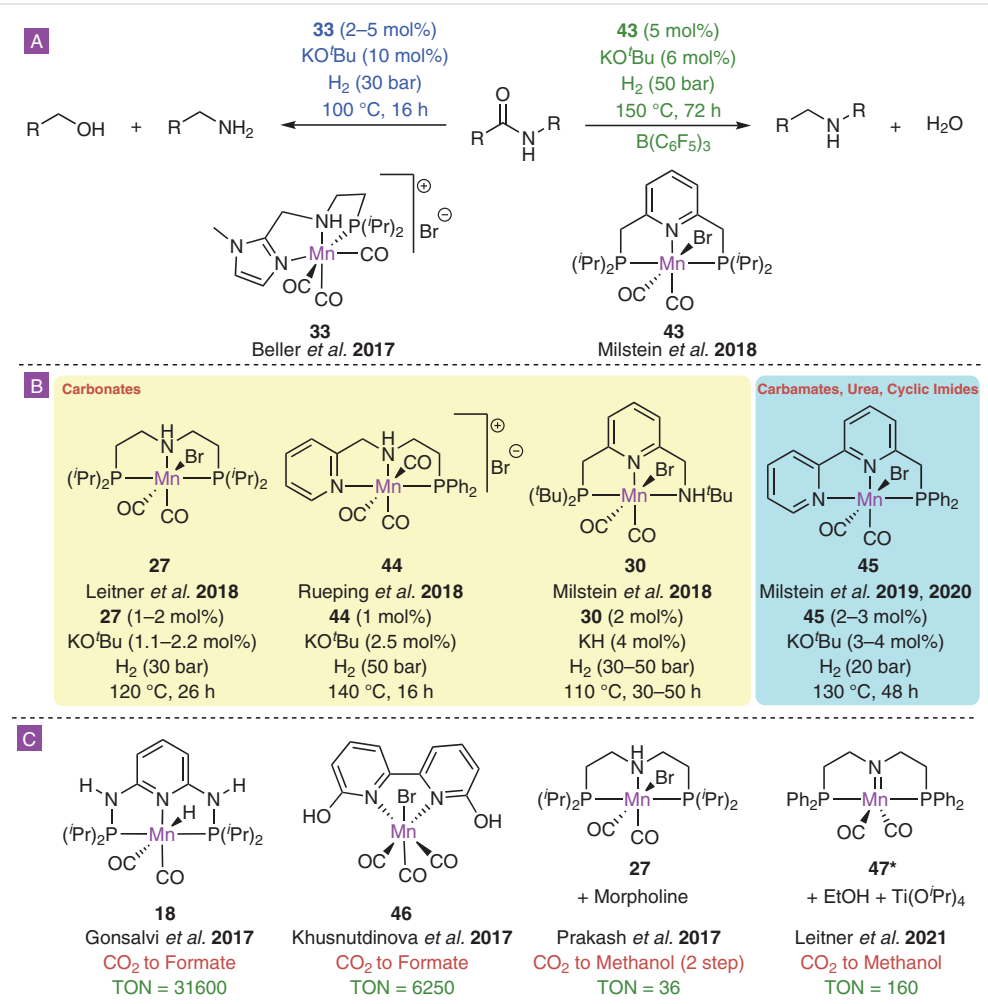

Scheme 8 Manganese catalysts for the hydrogenation of more challenging carbonyl groups: A. Different conditions and catalysts used for the reduction of amides to give either the deoxygenative product or a mixture of amines and alcohols; B. Conditions and catalysts for the reduction of challenging carbonyl-containing functional groups; $C$. Manganese catalysts for the hydrogenation of carbon dioxide

lower TON than their previous example. ${ }^{111}$ The group of Prakash performed the first reduction of carbon dioxide to methanol (TON = 36); a major limitation of the reaction was that it needed to be done in a stepwise process. ${ }^{112}$ More recently (2021), the group of Leitner made an important contribution to the field with a single-step hydrogenation of carbon dioxide to methanol. In their work, an isopropoxide metal salt was required to prevent the buildup of the resting state, a formate-manganese complex. In the presence of the PNP ('type B') catalyst $47^{*}$ and $\mathrm{Ti}\left(\mathrm{O}^{i} \mathrm{Pr}\right)_{4}$, carbon dioxide could be reduced to methanol with an increased TON of 160 (Scheme $8 \mathrm{C}$ ). ${ }^{113} \mathrm{CO}_{2}$ hydrogenation using a manganese catalyst has also been performed in silico to aid catalyst and reaction environment (i.e., solvent) design. ${ }^{114}$

Carbon monoxide hydrogenation to methanol was reported in 2019 by the group of Beller and Checinski. ${ }^{82}$ They used an amine-based promoter to capture the carbon monoxide, which generated a formamide that could then be reduced to methanol, re-forming the amine-based promotor. An important development came two years later from the Leitner group, in which the amine-based promotor was substituted with an alcohol. ${ }^{83 b}$ Using the same catalyst 27, in the presence of ethanol, an improved TON of 4023 was reached. The developments from the group of Leitner on alcohol-assisted direct reduction to methanol (from $\mathrm{CO}_{2}$ and
$\mathrm{CO}$ ) lead to the possibility of a catalytic 'breeding' of methanol, since the product, mediator, and, potentially, solvent can be identical. This was demonstrated by the group ${ }^{83 b, 113}$ and is summarized in Scheme 9.

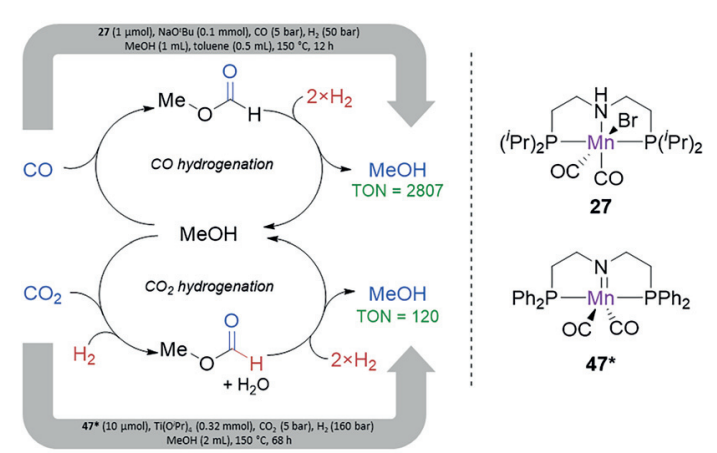

Scheme 9 Direct hydrogenation to methanol via a catalytic 'breeding' system presented by the group of Leitner

Kirchner, Rueping, and Beller have also separately contributed to the hydrogenation of $\mathrm{C}-\mathrm{C}$ double or triple bonds with $\mathrm{Mn}(\mathrm{I})$ catalysts (Scheme 10). Kirchner et al. hydrogenated a range of alkenes with their $\operatorname{Mn} \mathrm{n} P(\mathrm{CO})_{3}$ dippe catalyst 21 at low temperature $\left(25-60{ }^{\circ} \mathrm{C}\right)$ to afford the saturat- 
ed compounds in high yields. ${ }^{115}$ Rueping used Mn(I) catalyst 48 with an SNP pincer ligand to perform single hydrogenation of alkynes to afford Z-alkenes with high selectivity. ${ }^{116}$ Likewise, the group of Beller obtained Z-alkenes - from alkynes - almost exclusively via a concerted outer-sphere mechanism, using catalyst $27 .{ }^{117}$ The mild conditions (30$60{ }^{\circ} \mathrm{C}$ ) seemed critical for the selective single reduction, since the $Z$-alkene products could only be reduced to the corresponding alkanes at $140{ }^{\circ} \mathrm{C}$. The base also played a pivotal role in the reaction, recycling the thermodynamically stable and nonreactive off-cycle trans-hydride species.

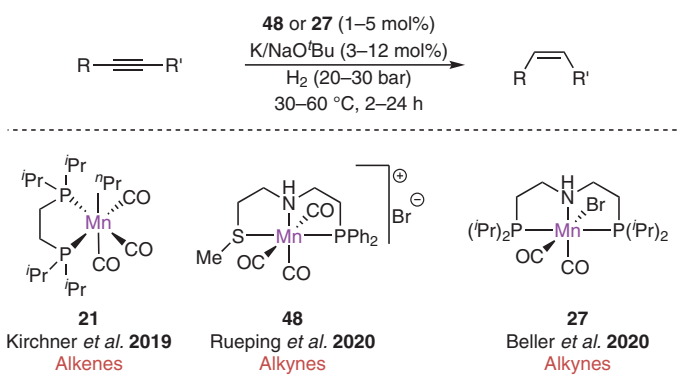

Scheme $10 \mathrm{C}-\mathrm{C} \pi$-bond hydrogenation using $\mathrm{Mn}(\mathrm{I})$ catalysts; reaction equation above shows reduction of alkynes to $Z$-alkenes under generic conditions

\section{Transfer Hydrogenation}

With the explosion of MLC manganese chemistry in 2016, the first transfer hydrogenation of ketones using a well-defined manganese catalyst was reported. The group of Beller tested multiple $\mathrm{Mn}(\mathrm{I})$ pincer complexes for the transfer hydrogenation of acetophenone using ${ }^{i} \mathrm{PrOH}$ as the hydrogen source. ${ }^{118}$ The best performing catalyst, the phosphine-free N,N,N-pincer complex 49 (Figure 9), could re- duce a large range of ketones under mild conditions via a convenient laboratory procedure that precludes the need for high pressure or more active and expensive silanes or boranes.

\subsection{Catalyst Overview}

Similarly to hydrogenation reactions, $\mathrm{Mn}(\mathrm{I})$ metal centers and MLC appear to be crucial components in the design of highly active catalysts. A common theme in almost all the catalysts was a Noyori-type $\mathrm{M}-\mathrm{NH}$ bond in the complex. The most significant differences in catalytic design between transfer hydrogenation catalysts and hydrogenation catalysts result from the, on average, lower temperature requirements for manganese-catalyzed transfer hydrogenation reactions. This allows for more readily available, easier to synthesize, and cheaper ligands. The added thermal stability from a tridentate ligand adds no detectable benefit in the room temperature to $60{ }^{\circ} \mathrm{C}$ transfer hydrogenation reactions. Sortais and co-workers explicitly explored this trait by reacting a range of 28 diamines with $\operatorname{MnBr}(\mathrm{CO})_{5} \cdot{ }^{119}$ The in situ generation of a bidentate ligated complex allowed good yields $(>65 \%)$ to be observed with eight of the diamines. This included using a chiral diamine $\mathbf{5 5}$ (Figure 9) to give $30-90 \%$ ee for the reduction of a range of benzylic ketones. ${ }^{119}$

\subsection{Development of Manganese-Catalyzed Trans- fer Hydrogenation Reactions}

Following the work of Beller in 2016, the groups of Sortais, ${ }^{120}$ Leitner, ${ }^{121}$ and Kundu ${ }^{122}$ added to this transfer hydrogenation work with similar bidentate nitrogen-based Mn(I) catalysts 50-52 (Figure 9). Later, Chen used the biomimetic-inspired bidentate catalyst $\mathbf{5 3},{ }^{123}$ similar to cata-

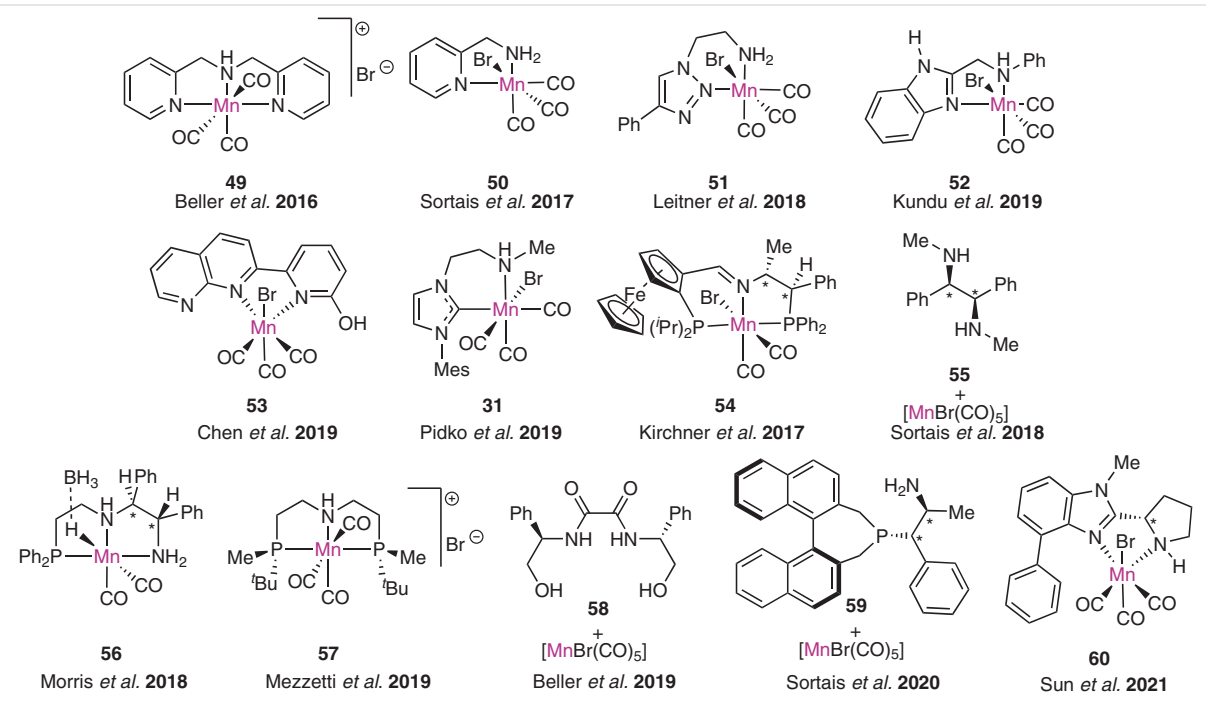

Figure 9 Manganese catalysts for the transfer hydrogenation of ketones to secondary alcohols 
lyst 46 used by the Khusnutdinova group for the hydrogenation of carbon dioxide (see Scheme 8C). Hydroxy deprotonation allowed for the transfer hydrogenation of ketones and aldehydes. Also, notably, Pidko used Mn-NHC complex 31 (Figure 9) at very low catalyst loading (75 ppm) to reduce ketones almost quantitatively. ${ }^{80}$

Multiple groups have also devised chiral ligand backbones to allow for the asymmetric reduction of ketones to afford enantiomerically enriched secondary alcohols (Figure 9). The group of Kirchner and Zirakzadeh used a ferrocenyl-containing PNP' pincer ligand in catalyst $\mathbf{5 4}$ to reduce acetophenone in up to $85 \%$ ee and full conversion. ${ }^{124}$ The group of Sortais used a cheaper, chiral diamine ligand $\mathbf{5 5}$ to generate the active species in situ, which afforded alcohols in high yield and ee. ${ }^{119}$ Morris and co-workers and, later, the Beller group also made chiral ligands for asymmetric trans- fer hydrogenation; ${ }^{125}$ however, they did not obtain the same ee levels. Mezzetti performed an in-depth analysis on the transfer hydrogenation of acetophenone derivatives using their manganese catalyst $\mathbf{5 7}$, despite particularly low ee values being observed for the alcohol products. ${ }^{126}$ In 2020 , Sortais screened a range of chiral PN bidentate ligands, with ligand 59 performing the best. ${ }^{127}$ Only mild improvements in ee values in comparison with their chiral NN bidentate system $\mathbf{5 5}$ were observed. In addition to minor mechanistic investigations reported in communications, Pidko et al. performed a thorough investigation, including computational analysis, of the asymmetric transfer hydrogenation of acetophenone using a simple chiral diamine ligand, inspired by the work of Sortais. ${ }^{128}$ Recently, another significant contribution to the field has been made by the group of Sun; ${ }^{129}$ by using complex $\mathbf{6 0}$, formed from an amino acid derived NN-
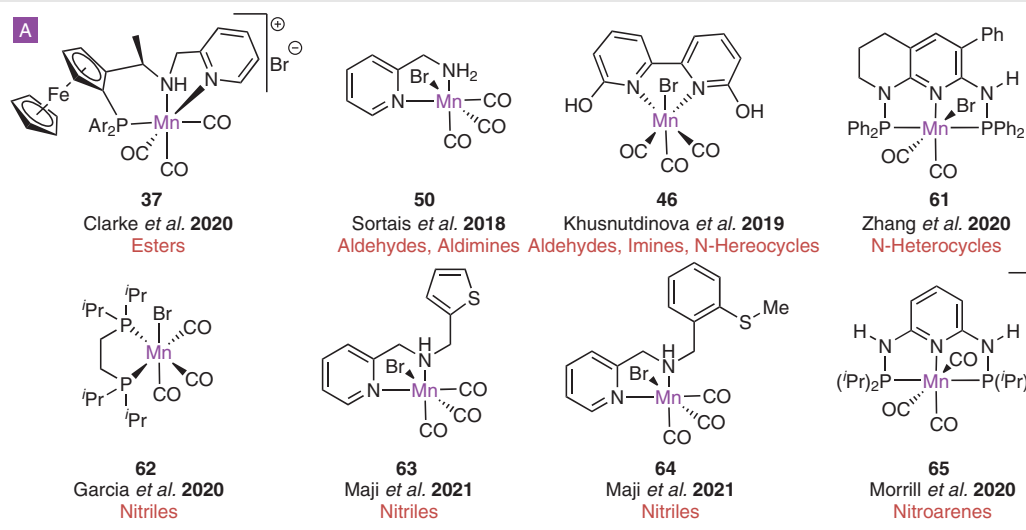

Zhang et al. 2020

$\mathrm{N}$-Heterocycles

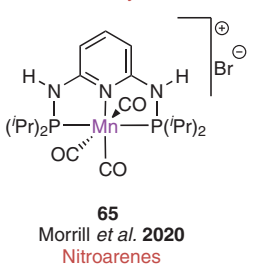

Zhang, Ci et al. 2020

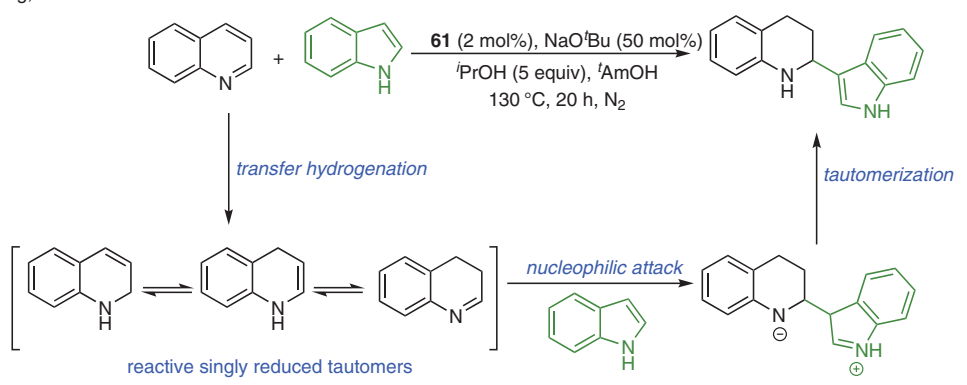

Maji, Adhikari et al. 2021

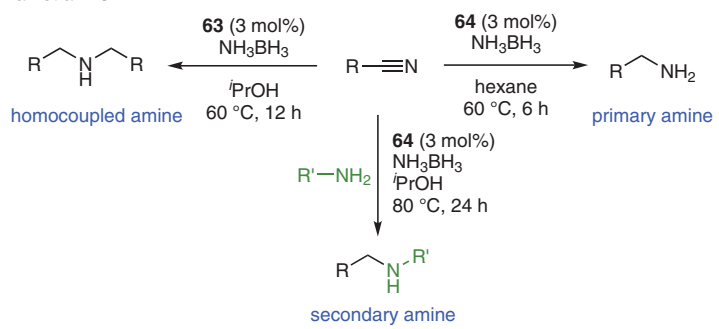

Scheme 11 A. Transfer hydrogenation catalysts for the reduction of aldehydes, imines, esters, and N-heterocycles (37, Ar = 3,5-dimethyl-4-methoxybenzene ${ }^{130}$ ); B. Reductive cross-coupling of N-heterocycles with an asymmetric $\mathrm{Mn}(\mathrm{I})$ base-activated transfer hydrogenation catalyst; $\mathrm{C}$. Switchable primary and secondary amine products from the transfer hydrogenation of nitriles using SNN-based manganese catalysts 


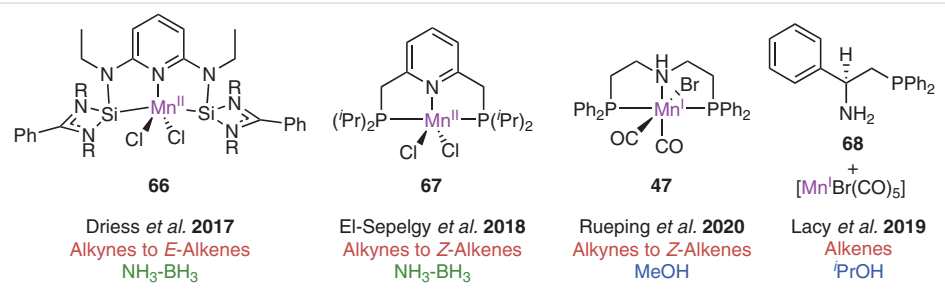

Figure 10 Manganese-based transfer hydrogenation catalysts for the reduction of $C-C \pi$-bonds $\left(66, R={ }^{t} B u^{135}\right)$

bidentate ligand and $\mathrm{MnBr}(\mathrm{CO})_{5}$, a range of benzyl ketones could be reduced in high yields (up to 90\%) and high ee values (up to 93\%). Computational calculations showed that $\pi-\pi$ stacking between the ligand and the substrate plays an important role in the enantiocontrol.

In 2020, Clarke et al. reported that catalyst 37 could be used for the double transfer hydrogenation of esters to give alcohols (Scheme 11). ${ }^{130}$ The reduction of $\mathrm{C}-\mathrm{N} \pi$-bonds was demonstrated independently by the groups of Khusnutdinova and Sortais in 2019.131 Both aldehydes and imines could be reduced in high yield by catalysts 46 and $\mathbf{5 0}$. In addition, Khusnutdinova showed that N-heterocycles could also be reduced, albeit in lower yield. In a specific study by Zhang and $\mathrm{Ci}$ (2020), the transfer hydrogenation of N-heterocycles was performed within a sequential cross-coupling reaction catalyzed by $\mathbf{6 1}$. Yields of up to $84 \%$ could be obtained (Scheme 11B). ${ }^{132}$

The Adhikari/Maji and Garcia groups both, separately, using $\mathrm{Mn}(\mathrm{I})$ catalysts 63/64 and 62 (Scheme 11), reduced nitriles using different hydrogen sources: the ammoniaborane complex and butan-2-ol, respectively. ${ }^{133}$ Both groups could isolate the primary amine in high yields; however, the group of Maji could also isolate the secondary amine by modifying the polarity of the solvent and optimizing with a modified catalyst (63). In addition, the nitrile could be coupled with a primary amine to create more diverse secondary amines (Scheme 11C). The group of Morrill used catalyst $\mathbf{6 5}$ (Scheme 11A), an outer-sphere variation of complex 18 (used by Kirchner and Gonsalvi; see Scheme 1), to reduce nitroarene compounds to their corresponding $\mathrm{N}$-methylarylamines by using methanol as both the hydrogen donor and methylation source. ${ }^{134}$

The ammonia-borane complex has also been used as a hydrogen source in multiple single reductions of alkynes to their corresponding alkenes. The Driess ${ }^{135}$ and El-Sepelgy/ Azofra ${ }^{136}$ groups could isolate $E$-alkenes and Z-alkenes, respectively (Figure 10). While both used Mn(II) pre-catalysts, Driess used an N-heterocyclic silylene backbone in $\mathbf{6 6}$, whereas El-Sepelgy and Azofra used a more traditional PNP backbone in 67 (Figure 10), typical on $\mathrm{Mn}(\mathrm{I})$ centers for both hydrogenation and transfer hydrogenation. Interestingly, the Mn(II) pre-catalyst was assumed to be reduced to a $\mathrm{Mn}(\mathrm{I})$ hydride prior to the catalytic cycle due to the presence of the ammonia-borane complex, a known reducing species. ${ }^{136}$ The group of Rueping continued the work on $Z$ alkene formation by using a Mn(I) catalyst (47; Figure 10) and methanol as the only sacrificial hydrogen source. ${ }^{137}$ The group of Lacy also managed to reduce $\mathrm{C}-\mathrm{C} \pi$-bonds on chalcones by using amino acid derived bidentate ligand 68 (Figure 10) and $\mathrm{MnBr}(\mathrm{CO})_{5} .{ }^{138}$

\section{Conclusion and Perspective}

Manganese has become a metal of great interest due to its chemical versatility and its high natural abundance. By using important catalytic design features that were initially developed on rare earth and noble metal catalysts to improve performance, the development of manganesecatalyzed reduction reactions has skyrocketed. With a future focus of chemistry being the 12 principles of green chemistry, the use of abundant metals and catalytic processes dictates that manganese catalysis can play an important role. However, continual development and increased understanding of the limitations of the current systems are still absolute requirements in replacing and ending the reliance on highly active rare earth and noble metals. We hope this report can assist in this regard, by highlighting current limitations and unknowns in the literature.

\section{Conflict of Interest}

The authors declare no conflict of interest.

\section{Funding Information}

We gratefully acknowledge the Max-Planck-Gesellschaft (Max Planck Society) for financial support.

\section{Acknowledgments}

We thank Prof. Dr. Walter Leitner for his insightful discussions as well as his generous support. 


\section{References}

(1) Haynes, W. M. CRC Handbook of Chemistry and Physics, 97th ed; CRC Press: Boca Raton, FL, 2016.

(2) U.S. Geological Survey Publications; https://pubs.usgs.gov/periodicals/mcs2021/mcs2021-manganese.pdf Last accessed: 17/11/2021.

(3) Cannon, W. F. In Fact Sheet; U.S. Geological Survey: Reston, VA, 2014, p. 2; http://pubs.er.usgs.gov/publication/fs20143087 DOI: $10.3133 /$ fs20143087.

(4) Kanady, J. S.; Tsui, E. Y.; Day, M. W.; Agapie, T. Science 2011, 333, 733.

(5) (a) Saisaha, P.; de Boer, J. W.; Browne, W. R. Chem. Soc. Rev. 2013, 42, 2059. (b) Miao, L.; Wang, J. L.; Zhang, P. Y. Appl. Surf. Sci. 2019, 466, 441.

(6) (a) Snider, B. B. Chem. Rev. 1996, 96, 339. (b) Davies, D. T.; Kapur, N.; Parsons, A. F. Tetrahedron 2000, 56, 3941.

(7) (a) Liu, W.; Ackermann, L. ACS Catal. 2016, 6, 3743. (b) Cano, R.; Mackey, K.; McGlacken, G. P. Catal. Sci. Technol. 2018, 8, 1251. (c) Hu, Y.; Zhou, B.; Wang, C. Acc. Chem. Res. 2018, 51, 816.

(8) (a) Valyaev, D. A.; Lavigne, G.; Lugan, N. Coord. Chem. Rev. 2016, 308, 191. (b) Carney, J. R.; Dillon, B. R.; Thomas, S. P. Eur. J. Org. Chem. 2016, 3912. (c) Jamatia, R.; Mondal, A.; Srimani, D. Adv. Synth. Catal. 2021, 363, 2969.

(9) Kuninobu, Y.; Sueki, S.; Kaplaneris, N.; Ackermann, L. In Catalysis with Earth-Abundant Elements, Chap. 6; Schneider, U.; Thomas, S., Ed.; Royal Society of Chemistry: Cambridge, 2020, 139-230.

(10) Olah, G. A. Angew. Chem. Int. Ed. 2005, 44, 2636.

(11) Suzuki, A. J. Organomet. Chem. 1999, 576, 147.

(12) (a) Khusnutdinova, J. R.; Milstein, D. Angew. Chem. Int. Ed. 2015, 54, 12236. (b) Weber, S.; Kirchner, K. In Metal-Ligand Co-operativity: Catalysis and the Pincer-Metal Platform; van Koten, G.; Kirchner, K.; Moret, M.-E., Ed.; Springer: Cham (Switzerland), 2020, 227-261. (c) Chatterjee, B.; Chang, W.-C.; Jena, S.; Werlé, C. ACS Catal. 2020, 14024. (d) Chatterjee, B.; Chang, W. C.; Werlé, C. ChemCatChem 2021, 13, 1659.

(13) Multiple mini-reviews focusing on aspects discussed within the larger field of manganese-catalyzed reductions are present in the literature; however, only the large ones, most relevant to this piece of work, have been mentioned and cited in the introduction, i.e., refs $14-20$.

(14) Garbe, M.; Junge, K.; Beller, M. Eur. J. Org. Chem. 2017, 4344.

(15) Mukherjee, A.; Milstein, D. ACS Catal. 2018, 8, 11435.

(16) (a) Kallmeier, F.; Kempe, R. Angew. Chem. Int. Ed. 2018, 57, 46. (b) Gorgas, N.; Kirchner, K. Acc. Chem. Res. 2018, 51, 1558. (c) Alig, L.; Fritz, M.; Schneider, S. Chem. Rev. 2019, 119, 2681.

(17) Maji, B.; Barman, M. K. Synthesis 2017, 49, 3377.

(18) Yang, X.; Wang, C. Chem. Asian J. 2018, 13, 2307.

(19) Azouzi, K.; Valyaev, D. A.; Bastin, S.; Sortais, J.-B. Curr. Opin. Green Sustain. Chem. 2021, 31.

(20) Wang, Y.; Wang, M.; Li, Y.; Liu, Q. Chem 2021, 7, 1180.

(21) Pratt, S. L.; Faltynek, R. A. J. Organomet. Chem. 1983, 258, C5.

(22) Hilal, H. S.; Abu-Eid, M.; Al-Subu, M.; Khalaf, S. J. Mol. Catal. 1987, 39, 1 .

(23) (a) Mao, Z.; Gregg, B. T.; Cutler, A. R. J. Am. Chem. Soc. 1995, 117, 10139. (b) DiBiase Cavanaugh, M.; Gregg, B. T.; Cutler, A. R. Organometallics 1996, 15, 2764.

(24) Chidara, V. K.; Du, G. D. Organometallics 2013, 32, 5034.
(25) (a) Zheng, J.; Elangovan, S.; Valyaev, D. A.; Brousses, R.; César, V.; Sortais, J.-B.; Darcel, C.; Lugan, N.; Lavigne, G. Adv. Synth. Catal. 2014, 356, 1093. (b) Valyaev, D. A.; Wei, D.; Elangovan, S.; Cavailles, M.; Dorcet, V.; Sortais, J. B.; Darcel, C.; Lugan, N. Organometallics 2016, 35, 4090.

(26) Magnus, P.; Waring, M. J.; Scott, D. A. Tetrahedron Lett. 2000, 41, 9731.

(27) (a) Zheng, J.; Chevance, S.; Darcel, C.; Sortais, J. B. Chem. Commun. 2013, 49, 10010. (b) Wei, D.; Buhaibeh, R.; Canac, Y.; Sortais, J. B. Chem. Commun. 2020, 56, 11617.

(28) Igarashi, M.; Mizuno, R.; Fuchikami, T. Tetrahedron Lett. 2001, $42,2149$.

(29) (a) Jetz, W.; Simons, P.; Thompson, J.; Graham, W. Inorg. Chem. 1966, 5, 2217. (b) Aylett, B.; Campbell, J. Inorg. Nucl. Chem. Lett. 1967, 3, 137. (c) Berry, A. D.; Macdiarm, A. G. Inorg. Nucl. Chem. Lett. 1969, 5, 601.

(30) Dong, J.; Yuan, X. A.; Yan, Z.; Mu, L.; Ma, J.; Zhu, C.; Xie, J. Nat. Chem. 2021, 13, 182.

(31) (a) Mukhopadhyay, T. K.; Flores, M.; Groy, T. L.; Trovitch, R. J. J. Am. Chem. Soc. 2014, 136, 882. (b) Trovitch, R. J. Acc. Chem. Res. 2017, 50, 2842.

(32) Pinto, M.; Friaes, S.; Franco, F.; Lloret-Fillol, J.; Royo, B. ChemCatChem 2018, 10, 2734.

(33) Antico, E.; Schlichter, P.; Werlé, C.; Leitner, W. JACS Au 2021, 1, 742.

(34) Obradors, C.; Martinez, R. M.; Shenvi, R. A. J. Am. Chem. Soc. 2016, 138, 4962.

(35) Docherty, J. H.; Peng, J.; Dominey, A. P.; Thomas, S. P. Nat. Chem. 2017, 9, 595.

(36) Carney, J. R.; Dillon, B. R.; Campbell, L.; Thomas, S. P. Angew. Chem. Int. Ed. 2018, 57, 10620.

(37) Mukhopadhyay, T. K.; Flores, M.; Groy, T. L.; Trovitch, R. J. Chem. Sci. 2018, 9, 7673.

(38) Yang, X.; Wang, C. Chin. J. Chem. 2018, 36, 1047.

(39) Yang, X.; Wang, C. Angew. Chem. Int. Ed. 2018, 57, 923.

(40) Liang, H.; Ji, Y. X.; Wang, R. H.; Zhang, Z. H.; Zhang, B. Org. Lett. 2019, 21, 2750.

(41) Son, S. U.; Paik, S. J.; Chung, Y. K. J. Mol. Catal. A: Chem. 2000, $151,87$.

(42) Mukhopadhyay, T. K.; Rock, C. L.; Hong, M.; Ashley, D. C.; Groy, T. L.; Baik, M. H.; Trovitch, R. J. J. Am. Chem. Soc. 2017, 139, 4901.

(43) Ghosh, C.; Mukhopadhyay, T. K.; Flores, M.; Groy, T. L.; Trovitch, R. J. Inorg. Chem. 2015, 54, 10398.

(44) Mukhopadhyay, T. K.; Ghosh, C.; Flores, M.; Groy, T. L.; Trovitch, R. J. Organometallics 2017, 36, 3477.

(45) Ma, X.; Zuo, Z.; Liu, G.; Huang, Z. ACS Omega 2017, 2, 4688.

(46) Yempally, V.; Shahbaz, A.; Fan, W. Y.; Madrahimov, S. T.; Bengali, A. A. Inorganics 2020, 8, 61.

(47) Saito, K.; Ito, T.; Arata, S.; Sunada, Y. ChemCatChem 2020, 13, 1152.

(48) Martínez-Ferraté, O.; Chatterjee, B.; Werlé, C.; Leitner, W. Catal. Sci. Technol. 2019, 9, 6370.

(49) (a) Behera, R. R.; Ghosh, R.; Panda, S.; Khamari, S.; Bagh, B. Org. Lett. 2020, 22, 3642. (b) Sousa, S. C. A.; Realista, S.; Royo, B. Adv. Synth. Catal. 2020, 362, 2437.

(50) Kelly, C. M.; McDonald, R.; Sydora, O. L.; Stradiotto, M.; Turculet, L. Angew. Chem. Int. Ed. 2017, 56, 15901.

(51) Igarashi, M.; Fuchikami, T. Tetrahedron Lett. 2001, 42, 1945.

(52) Arias-Ugarte, R.; Sharma, H. K.; Morris, A. L.; Pannell, K. H. J. Am. Chem. Soc. 2012, 134, 848.

(53) Ganguli, K.; Mandal, A.; Sarkar, B.; Kundu, S. Tetrahedron 2020, $76,131439$. 
(54) Bertini, F.; Glatz, M.; Stoger, B.; Peruzzini, M.; Veiros, L. F.; Kirchner, K.; Gonsalvi, L. ACS Catal. 2019, 9, 632.

(55) González, T.; García, J. J. Polyhedron 2021, 203, 115242.

(56) Zhang, G.; Zeng, H.; Wu, J.; Yin, Z.; Zheng, S.; Fettinger, J. C. Angew. Chem. Int. Ed. 2016, 55, 14369.

(57) Vijjamarri, S.; O'Denius, T. M.; Yao, B.; Kubatov, A.; Du, G. D. Organometallics 2020, 39, 3375.

(58) Vasilenko, V.; Blasius, C. K.; Wadepohl, H.; Gade, L. H. Angew. Chem. Int. Ed. 2017, 56, 8393.

(59) Barman, M. K.; Das, K.; Maji, B. J. Org. Chem. 2019, 84, 1570.

(60) Erken, C.; Kaithal, A.; Sen, S.; Weyhermüller, T.; Hölscher, M.; Werlé, C.; Leitner, W. Nat. Commun. 2018, 9, 4521.

(61) Nguyen, T. T.; Kim, J. H.; Kim, S.; Oh, C.; Flores, M.; Groy, T. L.; Baik, M. H.; Trovitch, R. J. Chem. Commun. 2020, 56, 3959.

(62) Garhwal, S.; Kroeger, A. A.; Thenarukandiyil, R.; Fridman, N.; Karton, A.; de Ruiter, G. Inorg. Chem. 2021, 60, 494.

(63) Brzozowska, A.; Zubar, V.; Ganardi, R. C.; Rueping, M. Org. Lett. 2020, 22, 3765.

(64) Weber, S.; Zobernig, D.; Stöger, B.; Veiros, L. F.; Kirchner, K. Angew. Chem. Int. Ed. 2021, 60, 24488.

(65) Kostera, S.; Peruzzini, M.; Kirchner, K.; Gonsalvi, L. ChemCatChem 2020, 12, 4625.

(66) Thenarukandiyil, R.; Satheesh, V.; Shimon, L. J. W.; de Ruiter, G. Chem. Asian J. 2021, 16, 999.

(67) Ghosh, P.; Jacobi von Wangelin, A. Angew. Chem. Int. Ed. 2021, 60,16035

(68) Zhang, G.; Zeng, H.; Li, S.; Johnson, J.; Mo, Z.; Neary, M. C.; Zheng, S. Dalton Trans. 2020, 49, 2610.

(69) Ghaffari, B.; Mendes-Burak, J.; Chan, K. W.; Coperet, C. Chem. Eur. J. 2019, 25, 13869.

(70) Elangovan, S.; Topf, C.; Fischer, S.; Jiao, H.; Spannenberg, A.; Baumann, W.; Ludwig, R.; Junge, K.; Beller, M. J. Am. Chem. Soc. 2016, $138,8809$.

(71) Elangovan, S.; Garbe, M.; Jiao, H.; Spannenberg, A.; Junge, K.; Beller, M. Angew. Chem. Int. Ed. 2016, 55, 15364.

(72) Kallmeier, F.; Irrgang, T.; Dietel, T.; Kempe, R. Angew. Chem. Int. Ed. 2016, 55, 11806.

(73) Espinosa-Jalapa, N. A.; Nerush, A.; Shimon, L. J. W.; Leitus, G.; Avram, L.; Ben-David, Y.; Milstein, D. Chem. Eur. J. 2017, 23, 5934.

(74) (a) Dub, P. A.; Henson, N. J.; Martin, R. L.; Gordon, J. C. J. Am. Chem. Soc. 2014, 136, 3505. (b) Dub, P. A.; Gordon, J. C. Nat. Rev. Chem. 2018, 2, 396.

(75) Papa, V.; Cao, Y. X.; Spannenberg, A.; Junge, K.; Beller, M. Nat. Catal. 2020, 3, 135.

(76) Pan, H. J.; Hu, X. Angew. Chem. Int. Ed. 2020, 59, 4942.

(77) Dubey, A.; Nencini, L.; Fayzullin, R. R.; Nervi, C.; Khusnutdinova, J. R. ACS Catal. 2017, 7, 3864.

(78) Wang, Y.; Zhu, L.; Shao, Z.; Li, G.; Lan, Y.; Liu, Q. J. Am. Chem. Soc. 2019, 141, 17337.

(79) Yang, W.; Chernyshov, I. Y.; van Schendel, R. K. A.; Weber, M.; Muller, C.; Filonenko, G. A.; Pidko, E. A. Nat. Commun. 2021, 12, 12.

(80) van Putten, R.; Benschop, J.; de Munck, V. J.; Weber, M.; Muller, C.; Filonenko, G. A.; Pidko, E. A. ChemCatChem 2019, 11, 5232.

(81) Papa, V.; Cabrero-Antonino, J. R.; Alberico, E.; Spanneberg, A.; Junge, K.; Junge, H.; Beller, M. Chem. Sci. 2017, 8, 3576.

(82) Ryabchuk, P.; Stier, K.; Junge, K.; Checinski, M. P.; Beller, M. J. Am. Chem. Soc. 2019, 141, 16923.

(83) (a) Kaithal, A.; Holscher, M.; Leitner, W. Angew. Chem. Int. Ed. 2018, 57, 13449. (b) Kaithal, A.; Werlé, C.; Leitner, W. JACS Au 2021, 1, 130.
(84) Bruneau-Voisine, A.; Wang, D.; Roisnel, T.; Darcel, C.; Sortais, J.B. Catal. Commun. 2017, 92, 1.

(85) Wei, D.; Bruneau-Voisine, A.; Chauvin, T.; Dorcet, V.; Roisnel, T.; Valyaev, D. A.; Lugan, N.; Sortais, J. B. Adv. Synth. Catal. 2018, $360,676$.

(86) Buhaibeh, R.; Filippov, O. A.; Bruneau-Voisine, A.; Willot, J.; Duhayon, C.; Valyaev, D. A.; Lugan, N.; Canac, Y.; Sortais, J. B. Angew. Chem. Int. Ed. 2019, 58, 6727.

(87) Glatz, M.; Stoger, B.; Himmelbauer, D.; Veiros, L. F.; Kirchner, K. ACS Catal. 2018, 8, 4009.

(88) Weber, S.; Brunig, J.; Veiros, L. F.; Kirchner, K. Organometallics 2021, 40, 1388.

(89) van Putten, R.; Uslamin, E. A.; Garbe, M.; Liu, C.; Gonzalez-deCastro, A.; Lutz, M.; Junge, K.; Hensen, E. J. M.; Beller, M.; Lefort, L.; Pidko, E. A. Angew. Chem. Int. Ed. 2017, 56, 7531.

(90) Liu, C.; van Putten, R.; Kulyaev, P. O.; Filonenko, G. A.; Pidko, E. A. J. Catal. 2018, 363, 136.

(91) Widegren, M. B.; Harkness, G. J.; Slawin, A. M. Z.; Cordes, D. B.; Clarke, M. L. Angew. Chem. Int. Ed. 2017, 56, 5825.

(92) Widegren, M. B.; Clarke, M. L. Org. Lett. 2018, 20, 2654.

(93) Garbe, M.; Junge, K.; Walker, S.; Wei, Z.; Jiao, H.; Spannenberg, A.; Bachmann, S.; Scalone, M.; Beller, M. Angew. Chem. Int. Ed. 2017, 56, 11237.

(94) (a) Ling, F.; Hou, H.; Chen, J.; Nian, S.; Yi, X.; Wang, Z.; Song, D.; Zhong, W. Org. Lett. 2019, 21, 3937. (b) Ling, F.; Chen, J. C.; Nian, S. F.; Hou, H. C.; Yi, X.; Wu, F. F.; Xu, M.; Zhong, W. H. Synlett 2020, 31, 285.

(95) Zeng, L. Y.; Yang, H. X.; Zhao, M. L.; Wen, J. L.; Tucker, J. H. R.; Zhang, X. M. ACS Catal. 2020, 10, 13794.

(96) Seo, C. S. G.; Tsui, B. T. H.; Gradiski, M. V.; Smith, S. A. M.; Morris, R. H. Catal. Sci. Technol. 2021, 11, 3153.

(97) (a) Zhang, L.; Tang, Y.; Han, Z.; Ding, K. Angew. Chem. Int. Ed. 2019, 58, 4973. (b) Zhang, L.; Wang, Z.; Han, Z.; Ding, K. Angew. Chem. Int. Ed. 2020, 59, 15565.

(98) Widegren, M. B.; Clarke, M. L. Catal. Sci. Technol. 2019, 9, 6047.

(99) (a) Garduño, J. A.; García, J. J. ACS Catal. 2018, 9, 392. (b) Weber, S.; Stoger, B.; Kirchner, K. Org. Lett. 2018, 20, 7212. (c) Weber, S.; Veiros, L. F.; Kirchner, K. Adv. Synth. Catal. 2019, 361, 5412.

(100)Wei, D.; Bruneau-Voisine, A.; Valyaev, D. A.; Lugan, N.; Sortais, J. B. Chem. Commun. 2018, 54, 4302.

(101) Freitag, F.; Irrgang, T.; Kempe, R. J. Am. Chem. Soc. 2019, 141, 11677.

(102)Wang, Z. L.; Chen, L.; Mao, G. L.; Wang, C. Y. Chin. Chem. Lett. 2020, 31, 1890

(103)Zubar, V.; Borghs, J. C.; Rueping, M. Org. Lett. 2020, 22, 3974.

(104) Liu, C.; Wang, M.; Liu, S.; Wang, Y.; Peng, Y.; Lan, Y.; Liu, Q. Angew. Chem. Int. Ed. 2021, 60, 5108.

(105)Zou, Y.-Q.; Chakraborty, S.; Nerush, A.; Oren, D.; Diskin-Posner, Y.; Ben-David, Y.; Milstein, D. ACS Catal. 2018, 8, 8014.

(106)(a) Kumar, A.; Janes, T.; Espinosa-Jalapa, N. A.; Milstein, D. Angew. Chem. Int. Ed. 2018, 57, 12076. (b) Zubar, V.; Lebedev, Y.; Azofra, L. M.; Cavallo, L.; El-Sepelgy, O.; Rueping, M. Angew. Chem. Int. Ed. 2018, 57, 13439.

(107)Das, U. K.; Kumar, A.; Ben-David, Y.; Iron, M. A.; Milstein, D. J. Am. Chem. Soc. 2019, 141, 12962.

(108) Das, U. K.; Janes, T.; Kumar, A.; Milstein, D. Green Chem. 2020, 22, 3079.

(109) Bertini, F.; Glatz, M.; Gorgas, N.; Stoger, B.; Peruzzini, M.; Veiros, L. F.; Kirchner, K.; Gonsalvi, L. Chem. Sci. 2017, 8, 5024.

(110) Kumar, A.; Daw, P.; Espinosa-Jalapa, N. A.; Leitus, G.; Shimon, L. J. W.; Ben-David, Y.; Milstein, D. Dalton Trans. 2019, 48, 14580.

(111) Kostera, S.; Weber, S.; Peruzzini, M.; Veiros, L. F.; Kirchner, K.; Gonsalvi, L. Organometallics 2021, 40, 1213. 
(112) Kar, S.; Goeppert, A.; Kothandaraman, J.; Prakash, G. K. S. ACS Catal. 2017, 7, 6347.

(113) Kuß, D. A.; Hölscher, M.; Leitner, W. ChemCatChem 2021, 13, 3319.

(114) (a) Rawat, K. S.; Mahata, A.; Choudhuri, I.; Pathak, B. J. Phys. Chem. C 2016, 120, 16478. (b) Zhang, L.; Pu, M.; Lei, M. Dalton Trans. 2021, 50, 7348.

(115) Weber, S.; Stoger, B.; Veiros, L. F.; Kirchner, K. ACS Catal. 2019, 9, 9715.

(116)Zubar, V.; Sklyaruk, J.; Brzozowska, A.; Rueping, M. Org. Lett. 2020, 22, 5423.

(117) Garbe, M.; Budweg, S.; Papa, V.; Wei, Z. H.; Hornke, H.; Bachmann, S.; Scalone, M.; Spannenberg, A.; Jiao, H. J.; Junge, K.; Beller, M. Catal. Sci. Technol. 2020, 10, 3994.

(118) Perez, M.; Elangovan, S.; Spannenberg, A.; Junge, K.; Beller, M. ChemSusChem 2017, 10, 83.

(119)Wang, D.; Bruneau-Voisine, A.; Sortais, J. B. Catal. Commun. 2018, 105, 31.

(120) Bruneau-Voisine, A.; Wang, D.; Dorcet, V.; Roisnel, T.; Darcel, C.; Sortais, J. B. Org. Lett. 2017, 19, 3656.

(121) Martinez-Ferrate, O.; Werlé, C.; Franciò, G.; Leitner, W. ChemCatChem 2018, 10, 4514.

(122) Ganguli, K.; Shee, S.; Panja, D.; Kundu, S. Dalton Trans. 2019, 48, 7358.

(123)Zhang, C.; Hu, B. W.; Chen, D. F.; Xia, H. P. Organometallics 2019, $38,3218$.

(124)Zirakzadeh, A.; de Aguiar, S. R. M. M.; Stoger, B.; Widhalm, M.; Kirchner, K. ChemCatChem 2017, 9, 1744.

(125) (a) Demmans, K. Z.; Olson, M. E.; Morris, R. H. Organometallics 2018, 37, 4608. (b) Schneekönig, J.; Junge, K.; Beller, M. Synlett 2019, 30, 503.
(126) Passera, A.; Mezzetti, A. Adv. Synth. Catal. 2019, 361, 4691.

(127) Azouzi, K.; Bruneau-Voisine, A.; Vendier, L.; Sortais, J.-B.; Bastin, S. Catal. Commun. 2020, 142, 106040.

(128) van Putten, R.; Filonenko, G. A.; Gonzalez de Castro, A.; Liu, C.; Weber, M.; Muller, C.; Lefort, L.; Pidko, E. Organometallics 2019, $38,3187$.

(129) Wang, L. X.; Lin, J.; Sun, Q. S.; Xia, C. G.; Sun, W. ACS Catal. 2021, $11,8033$.

(130) Oates, C. L.; Widegren, M. B.; Clarke, M. L. Chem. Commun. 2020, $56,8635$.

(131) (a) Wei, D.; Bruneau-Voisine, A.; Dubois, M.; Bastin, S.; Sortais, J. B. ChemCatChem 2019, 11, 5256. (b) Dubey, A.; Rahaman, S. M. W.; Fayzullin, R. R.; Khusnutdinova, J. R. ChemCatChem 2019, 11, 3844.

(132)Tan, Z. D.; Xiong, B. A.; Yang, J.; Ci, C. G.; Jiang, H. F.; Zhang, M. J. Catal. 2020, 392, 135.

(133) (a) Garduño, J. A.; Flores-Alamo, M.; García, J. J. ChemCatChem 2019, 11, 5330. (b) Sarkar, K.; Das, K.; Kundu, A.; Adhikari, D.; Maji, B. ACS Catal. 2021, 11, 2786.

(134) Reed-Berendt, B. G.; Mast, N.; Morrill, L. C. Eur. J. Org. Chem. 2020, 1136.

(135)Zhou, Y. P.; Mo, Z.; Luecke, M. P.; Driess, M. Chem. Eur. J. 2018, $24,4780$.

(136) Brzozowska, A.; Azofra, L. M.; Zubar, V.; Atodiresei, I.; Cavallo, L.; Rueping, M.; El-Sepelgy, O. ACS Catal. 2018, 8, 4103.

(137) Sklyaruk, J.; Zubar, V.; Borghs, J. C.; Rueping, M. Org. Lett. 2020, 22, 6067.

(138) Vigneswaran, V.; MacMillan, S. N.; Lacy, D. C. Organometallics 2019, 38, 4387. 